() 2015, Elsevier. Licensed under the Creative Commons Attribution-NonCommercial-NoDerivatives 4.0 International http://creativecommons.org/licenses/by-nc-nd/4.0/

\title{
Conceptualizing Leadership Perceptions as Attitudes: Using Attitude Theory to Further Understand the Leadership Process
}

\author{
Allan Lee ${ }^{1}$, Robin Martin ${ }^{1}$, Geoff Thomas ${ }^{2}$, Yves Guillaume ${ }^{3}$ and Greg Maio ${ }^{4}$ \\ ${ }^{1}$ Alliance Manchester Business School, University of Manchester \\ ${ }^{2}$ Surrey Business School, University of Surrey \\ ${ }^{3}$ Aston Business School, Aston University \\ ${ }^{4}$ Cardiff University
}

\section{Authors Information:}

Allan Lee: Alliance Manchester Business School, Booth Street East, Manchester, M15 6PB, UK, (e-mail: allan.lee@ mbs.ac.uk; Tel: +447888657094)

Robin Martin: Alliance Manchester Business School, Booth Street East, Manchester, M15 6PB, UK, (e-mail: robin.martin@mbs.ac.uk; Tel: +447888657094)

Geoff Thomas: Surrey Business School, University of Surrey, Guildford, Surrey, GU2 7XH, UK, (email: gt0011@surrey.ac.uk)

Yves Guillaume, Aston Business School, Aston University, Birmingham, B4 7ET, UK, (email: Y.R.F.GUILLAUME2@aston.ac.uk)

Greg Maio, Cardiff University, School of Psychology, Cardiff, CF10 3XQ, UK, (email: Maio@cardiff.ac.uk) 


\begin{abstract}
Leadership is one of the most examined factors in relation to understanding employee wellbeing and performance. While there are disparate approaches to studying leadership, they share a common assumption that perceptions of a leader's behavior determine reactions to the leader. The concept of leadership perception is poorly understood in most theoretical approaches. To address this, we propose that there are many benefits from examining leadership perceptions as an attitude towards the leader. In this review, we show how research examining a number of aspects of attitudes (content, structure and function) can advance understanding of leadership perceptions and how these affect work-related outcomes. Such a perspective provides a more multi-faceted understanding of leadership perceptions than previously envisaged and this can provide a more detailed understanding of how such perceptions affect outcomes. In addition, we examine some of the main theoretical and methodological implications of viewing leadership perceptions as attitudes to the wider leadership area. The cross-fertilization of research from the attitudes literature to understanding leadership perceptions provides new insights into leadership processes and potential avenues for further research.
\end{abstract}




\section{Introduction}

Effective leadership offers a solution to the problem of how to organize collective effort; consequently, it is central to organizational effectiveness (Hogan \& Kaiser, 2005). Leadership has been investigated from a variety of perspectives. Indeed, myriad theories exist attempting to describe leadership and ultimately to explain how leadership influences employee attitudes and behaviors. Currently, popular theories include transformational leadership (e.g., Bass, 1985; Bass \& Avolio, 1990), leader-member exchange (LMX; e.g., Graen \& Uhl-Bien, 1995) and servant leadership (e.g., Greenleaf, 1977).

While there are differences between the various theories, the underlying common theme is that they draw upon the process of leadership perceptions (from both the follower and leader) as determinants of reactions to the leadership process. Leadership theories typically measure the leader's leadership style by asking followers whether or not their leader acts in a way that represents that style of leadership. Thus it can be argued that the vast majority of leadership research is based on the measurement of follower's perceptions of their leader. This commonality is important as leadership perceptions typically represent followers' subjective evaluations and judgments of leadership and therefore, as argued in this review, are synonymous with the way attitudes are conceptualized.

In this context, we refer to attitudes as an evaluation of an object in terms of the degree of it being favorable or unfavorable (e.g., Eagly \& Chaiken 1993). Of relevance, job attitudes is one of the most central and enduring constructs in individual-level organizational research (Harrison, Newman, \& Roth, 2006). Common job attitudes that are examined include work attitudes, job satisfaction, or organizational commitment (Judge \& Kammeyer-Mueller, 2012). We propose that leadership perceptions can also be considered an attitude. For example, judgments concerning the quality of leader-member relationships can be considered a relationship attitude while servant leadership reflects followers' attitude to the degree that their leader demonstrates this style. 
The aim of this review is to show how the application of theory and research into attitudes can be a useful framework for understanding leadership perceptions and therefore, ultimately, leadership effectiveness. While there is a literature examining evaluations of the leader (such as supervision satisfaction, Kinicki, McKee-Ryan, Schriesheim, \& Carson, 2002), this has primarily relied on global evaluations rather than exploring the nuances associated with various aspects that comprise an attitude. Therefore, we believe that this is the first systematic application of attitude theory to understanding leadership perceptions and we believe there are six main benefits of this approach.

First, the adoption of an attitudes framework moves research away from a leadercentric approach, that assumes leadership measures accurately reflect leader's behaviors, to a more follower-centric approach that characterizes leadership perceptions as a property of both the follower and the leader (Thomas, Martin, \& Riggio, 2013).

Second, the application of attitude research to leadership perceptions gives new and important insights into aspects of its underlying content, structure and functions that hitherto have not been extensively explored. For example, based on attitude research it can be suggested that leadership perceptions are composed of three components (affect, cognition and behavior) and this tripartite framework can provide a more differentiated understanding of leadership perceptions than is currently the case.

Third, the use of an attitudes framework offers insights into the nature of leadership perceptions and new ways to understand how these attitudes can be formed, maintained and enhanced. For example, an important characteristic of attitudes is its strength (i.e., the extent to which one's evaluation is crystallized and enduring) with strongly held attitudes more difficult to change than weakly held attitudes. Applying this to leadership perceptions aids understanding of why such perceptions may be stable over time and are difficult to change.

Fourth, attitude research has extensively examined the relationship between both implicit and explicit attitudes and consequences such as information processing, persistence 
and behavior. Frameworks such as the Theory of Planned Behavior (Ajzen, 1988) and Motivation and Opportunity as Determinants model (Fazio,1990), which both examine the attitude-behavior link, can be utilized to extend understanding of the link between both implicit and explicit leadership perceptions and work outcomes such as performance.

Fifth, the application of an attitudes framework provides a common understanding of leadership perceptions across many different leadership approaches providing a unifying theme. As our review will demonstrate there is considerable variation in the extent that leadership measures contain items that correspond to the different attitudinal components. This variation, we suggest, might explain inconsistencies between different leadership measures and various outcomes.

Finally, the greater understating of leadership perceptions that arise from using an attitudes framework gives many practical implications concerning leadership development and training programmes. Most leadership programmes focus on developing leaders' skills or meta-competencies (Day, 2001) while this review shows that it is equally important for leaders to understand the processes that followers engage in interpreting their behaviors. If leaders understand that their follower's perceptions are attitudes (and not simple evaluations), then they can develop an insight into how these attitudes form and how to change them.

The review is presented in two parts. In the first part we show how research and theory in attitudes can inform leadership perceptions with relevance to three main aspects of attitudes: content, structure and function. Given space limitations, we have focused on some of the main contemporary leadership theories to illustrate the benefits of the cross-fertilization but we recognise that this analysis could apply to a broader range of theories. In the second part we explore the theoretical and practical implications of our analysis and suggest avenues for future research. In this section we specifically focus on the implications of examining leadership perceptions as an attitude for understanding the leadership process.

\section{Attitude content}


In this section, we outline how using attitude theory can provide new insights into understanding the content of leadership perceptions.

\subsection{A tripartite view of attitudes: Affect, cognition and behavior}

The definition above highlights that attitudes refer to an overall evaluation of objects (Eagly \& Chaiken, 1993). Attitudes are evaluative in that they reflect the degree that our response to objects are positive and approach-oriented versus negative and avoidance-oriented (Eaton et al., 2008). But what are these evaluation based on? Why do people develop strong thoughts and feelings about objects such as, places, politicians, sports teams, films, and, of interest to this article, leaders? Research shows such favorability arises because of individuals' beliefs, feelings, and past experiences regarding such objects. It has been suggested that evaluative responses can be classified into affective, cognitive or behavioral components of an attitude or a combination thereof (e.g., Allport, 1935; Harding, Kutner, Proshansky, \& Chein, 1954; Katz \& Stotland, 1959; Rosenberg \& Hovland, 1960; Zanna \& Rempel, 1984, 1988). Olson and Zanna (1993) summarise the tripartite model of attitudes by stating that most attitude researchers agree that " “...evaluation constitutes a central, perhaps predominant, aspect of attitudes" and " ... affective cognitive and behavioral antecedents of attitudes can be distinguished"' (p. 119).

In general, people who have a positive attitude toward an attitude object tend to have aligned attitudinal components, whereby cognition, affect and behavior are uniformly favorable toward the object, whereas people with negative attitudes regarding an attitude object have unfavorable affective, cognitive and behavioral components that express unfavorability toward the object (see Eagly \& Chaiken, 1993). However, people's feelings, beliefs and behaviors toward an object can sometimes differ in their valence (direction) and have implications for their overall attitude (Haddock \& Maio, 2004). Furthermore, empirical studies demonstrate that some attitudes are uniquely related to feelings about the attitude object, whereas other attitudes are uniquely related to beliefs about the attitude object. Such findings have showed low to 
moderate correlations between the different components of attitudes toward a large variety of issues. For example, feelings (i.e. affect) are particularly strong indicators of attitudes toward blood donation (Breckler \& Wiggins, 1989), smoking (Trafimow \& Sheeran, 1998), condom use (de Wit, Victoir, \& Van den Bergh, 1997), deaf people (Kiger, 1997), politicians (Glaser \& Salovey, 1998), and alcohol and marijuana use in frequent users of these drugs (Simons \& Carey, 1998). Conversely, cognitions are strong predictors of reactions to persuasive messages (Breckler \& Wiggins, 1991) and attitudes toward a variety of controversial social issues (e.g., capital punishment, legalized abortion, and nuclear weapons; Breckler \& Wiggins, 1989; Crites, Fabrigar, \& Petty, 1994).

These findings were supported by a meta-analytic analysis that highlights the importance of what the authors called 'hedonic-instrumental correspondence'(Glasman \& Albarracin, 2006). Hedonically-orientated behaviors tend to be affectively driven (e.g., the desire to play games), whereas instrumentally-orientated behaviors (e.g., studying for an exam), are more likely to be cognitively driven (Millar \& Millar, 1998; Millar \& Tesser, 1992). The meta-analytic results show that focusing on the affective components of one's attitude leads to greater behavior correlation when the behavior is hedonic in nature. Conversely, focusing on feelings may decrease attitude-behavior correspondence when the behavior is instrumental. The reverse is also true (Glasman \& Albarracin, 2006). There is also evidence to show that attitude-relevant feelings and beliefs are also clustered separately in memory (Trafimow \& Sheeran, 1998).

\subsection{Content of leadership measures}

Since we propose that leadership perceptions can be conceptualized as attitudes, then it is important to examine the extent that current measures of leadership perceptions cover the three components of attitudes we described above (i.e., affect, cognition and behavior). For example, one of the most popular scales for measuring LMX quality (LMX-MDM, Liden \& Maslyn, 1998) distinguishes between the degree that the leader-follower relationship is based 
on four 'currencies of exchange': liking one another (affect), loyalty to each other (loyalty), reputation (professional respect), and task-related behaviors (contribution). This scale provided the additional dimension of professional respect to previous multidimensional LMX scales (e.g., Dienesch, 1985; Phillips, Duran, \& Howell, 1993; Schriesheim, Neider, Scandura, \& Tepper, 1992). It is important to determine whether these dimensions map onto the tripartite model of attitudes described above. For example, one would expect the 'affect' dimension of the LMX-MDM to tap into followers' affective component of their attitude toward the dyadic relationship. In addition, the 'contribution' dimension of the LMX-MDM measure should tap into the behavioral component of their attitude as it relates to the current level of work-oriented activity each member puts forth. The LMX-MDM, therefore, is one of the few examples of a leadership measure that, theoretically, should capture distinct attitudinal components.

In the context of the current review it is important to determine the extent that current leadership measures contain items that measure the three components of attitudes (i.e., affect, cognition, and behavior). Since the majority of these measures have not been previously classified in this way (for exception see Schriesheim \& Liu, 2013), the authors conducted an initial content analysis of the items in a number of prominent leadership measures. We acknowledge that this is not a rigorous approach but we did this to illustrate the extent that different leadership measures contain items that reflect the three components of attitudes. We chose some of the most popular measures of leadership perceptions from a variety of theoretical orientations. Each of the five authors independently coded the extent to which each of the items for the leadership measures were predominantly affectively-, cognitively- or behaviorally-orientated (see Table 1). We then summed the ratings across the five authors and identified items where there was a high level of agreement (i.e., at least 3 out of 5 agreed on same dimension).

Insert Table 1 About here 
Referring to Table 1, a number of interesting observations can be made. There is considerable variation both within and between leadership measures in the extent that they contain items that fall into the three attitudinal components. Across all the leadership measures, cognitive items were the most frequent (71\%), followed by affective (25\%), with very few behavioral items (4\%). With reference to the LMX-MDM scale we described above, it is notable that there were items in each of the three attitudinal dimensions. As expected, all three items in the LMX-MDM 'affect' dimension were rated as being affective by the authors. With respect to the 'contribution' dimension of the LMX-MDM, only two items were rated as behavioral and the remaining item as being affective. The other items in the LMX-MDM measure were rated as either affective or cognitive. In terms of the other leadership measures, some were rated as purely cognitive (such as, Authentic Leadership Inventory, Neider, \& Schriesheim, 2011: Authentic Leadership Questionnaire, Walumbwa, Avolio, Gardner, Wernsing, \& Peterson, 2008), some purely affective (such as, Abusive Supervision Scale, Tepper, 2000), and finally some a mixture of different attitudinal components (such as, Transformational Leadership, Avolio \& Bass, 1999: Ethical Leadership, Brown, Trevino, \& Harrison, 2005).

Some items were difficult to code in that there was low consensus amongst the authors. This is not surprising for several reasons. First, the tripartite attitude classification is a heuristic guide and, in fact, many attitude items can be composed of a mixture of dimensions (Olson \& Zanna, 1993). Second, the leadership measures we reviewed have not been explicitly designed to capture particular attitude content and therefore are likely to capture a range of evaluative responses. An example of this is the Abusive Supervision measure (Tepper, 2000) that asks respondents to judge how often their supervisor, for example, ridicules them, or invades their privacy. Such items ask for a cognitive evaluation of their leader's behavior but, due to the very negative nature of the behavior being assessed, it is highly likely to lead to an affective reaction. 
While Table 1 provides a useful starting point to classify the content of leadership items, we do not claim that our ratings reflect a rigorous evaluation of the content of leadership measures. Therefore, following a technique developed by Hinkin and Tracey (1999) we conducted a more comprehensive content validity assessment, on a smaller number of leadership scales, using a method that utilizes analysis of variance (ANOVA) to empirically test item distinctiveness. This technique can be used with relatively small sample sizes (Hinkin $\&$ Schriesheim, 2008), and has been used previously to investigate the content validity of leadership measures (Hinkin \& Schriesheim, 2008). For example, Schriesheim and Liu (2013) recently used the technique to assess the extent that the items in the LMX scales measure the three components of attitudes. Using this analysis we asked a panel of university faculty and doctoral students (in the fields of Organizational Behavior or Social Psychology) to assess the extent that measures of leadership reflected the various attitude components (affect, cognition and behavior). For each leadership item the raters $(\mathrm{N}=28)$ indicated the extent that they felt it was affective, cognitive and behavioral. So, for example, for the following item from the TLI scale (Podsakoff et al. 1990); “My supervisor has a clear understanding of where we are going", respondents were asked to indicate on three separate scales the degree to which the item reflected an affective, cognitive and behavioral attitude component (each rated on a scale from strongly disagree - strongly agree). We then calculated the extent that each item represented a distinct attitude component using ANOVA to compare the mean scores. As respondents were asked to provide three rating for each leadership item, we limited our assessment to four leadership scales, which represent three contemporary and popular theories of leadership (LMX, transformational and authentic; see appendix 1 for items). The results of this content assessment can be seen in Table 2.

\section{$\underline{\text { Insert Table } 2 \text { About Here }}$}

Table 2 has many similarities to the initial assessment shown in Table 1 . The items in the LMX-7 scale (Graen \& uhl-Bien, 1995) were rated as largely cognitive in both analyses. 
The same is true of the Transformational Leadership Inventory (TLI; Podsakoff et al. 1990), which was also viewed as largely cognitive by both sets methods. Differences, however, were evident when comparing the LMX-MDM measure (Liden \& Maslyn, 1998). Namely, the authors categorized the scale as mainly affective (see Table 1); with half of the items being rated this way, In contrast, Table 2 shows that the larger panel of raters only rated three items as clearly affective. On many of the items respondents failed to clearly distinguish between affective and cognitive components, with four of the twelve items showing a lack of distinctiveness between components. Interestingly, similar findings were shown in the analysis conducted by Schriesheim and Liu (2013), which demonstrated that the subject matter experts also struggled to classify many of the LMX-MDM items as distinctively cognitive, behavioral or affective. As discussed earlier, this is not surprising as attitude scales do not always clearly relate to just one attitude component and the leadership scales were not designed to focus on a particular attitude component.

It is often the case that the language used in attitudinal items can make it hard to distinguish which component of an attitude it is addressing. This is particularly true when trying to distinguish between affective and cognitive components. Take, for example, the following item from the LMX-MDM scale: "I admire my supervisor's professional skills". The word 'admire' might suggest, to some, that this is an affective component of an attitude, as admiration might be considered to indicate a positive emotion felt towards the supervisor. Others, however, might view this item as an indication of a cognitive component as it represents a person's beliefs about the professional abilities of their leader. In other cases attitude items may contain a mixture of attitudinal components. The following item from the TLI (Podsakoff et al., 1990) can be argued to contain both affective and cognitive components: "My supervisor shows respect for my personal feelings". The item, which as Table 2 shows was not clearly rated as either affective or cognitive, is asking respondents to make a cognitive judgement about whether or not there think their supervisor acts in a certain way. However, the 
item also asks about personal feelings, which indicates it also has an affective component. For instance, if a respondent indicates that the supervisor does not respect their personal feelings this would presumably indicate a negative affective reaction.

To conclude, Tables 1 and 2 provide a preliminary illustration demonstrating that leadership measures contain a range of different attitudinal components. As reviewed above there was a wide variation in the types of attitudinal components in many of the leadership measures. This observation is important because, as will be illustrated throughout this review, the different attitudinal components have effects on a range of processes and outcomes that are relevant to leadership research. The findings also highlight the benefit of future research that focuses on the development of leadership scales that take into account the tripartite view of attitudes. Specifically, developing scales that clearly distinguish and measure affective, cognitive and behavioral components of leadership attitudes can facilitate an understanding of the how different components influence different outcomes.

\subsection{Differential impact of tripartite content on outcomes}

One of the reasons to examine the attitudinal components in leadership measures is because it is likely that they have a differential impact on important work-related outcomes. One might expect there to be consistency between the three attitudinal components and corresponding work outcomes (attitudinal component-outcome consistency). For example, one might expect affectively-based measures to predict hedonic (i.e. affective) outcomes (such as, affective organizational commitment), cognitively-based attitudinal measures to predict instrumental (i.e. cognitive) outcomes (such as, organizational identification), and behaviorally-based attitudinal measures to predict behavioral outcomes (such as, task performance).

There is relatively little research in the leadership domain that examines the impact of the different attitudinal components on work-related outcomes. As an exception, the LMXMDM (Liden \& Maslyn, 1998) described above, examined the association between the four 
different dimensions and various employee outcomes, including; organizational commitment, turnover intentions, satisfaction with supervision and leader-rated performance. The results give some support for attitudinal content-outcome consistency. For example, the 'affect' and 'professional respect' dimensions of the LMX-MDM (which were rated as affective in our content analysis) both predicted an affective outcome (i.e., supervisor satisfaction). Likewise, the 'contribution' dimension of the LMX-MDM (which was rated as behavioral in our content analysis) predicted supervisor-rated performance.

Others studies have also examined the relation between the dimensions of LMX-MDM and various outcomes. While it is difficult to determine a clear pattern between the studies, there is evidence that the 'affect' dimension was a strong predictor of affective-based outcome such as, organizational commitment and supervisor satisfaction (Ansari, Hung, \& Aafaqi, 2007; Greguras \& Ford, 2006; Settoon, Bennett, \& Liden, 1996; Wang, Law, \& Chen, 2008). However, some studies do not support the attitudinal content-outcome consistency. For example, some studies found that the 'loyalty' dimension (which according to Table 2 is mainly cognitive-based) best predicted task performance (Greguras \& Ford, 2006; Law, Wang, \& Hui, 2010) and OCB (Lo, Ramayah, \& Hui, 2006). Given the paucity of research in this area we cannot draw firm conclusions but the above research highlights the fact that the relation between leadership perceptions and work-related outcomes is likely to be affected by the content of attitudinal measures and the type of outcome examined.

The issue of correspondence between attitudinal components and outcomes raises the interesting question of how to classify particular leadership outcomes. Many of the commonly measured outcomes of leadership also reflect perceptions, either leader or follower, and attitudes. Some of these outcomes are explicitly considered to be attitudinal, such as job satisfaction and organizational commitment. Scholars have noted that job satisfaction measures do not purely represent either affective or cognitive components of an attitude, with scales likely containing some degree of affect and cognition (e.g., Fisher, 2000; Weiss, 2002). 
However, based on a content assessment of two popular job satisfaction measures, Schleicher, Watt and Greguras (2004) highlighted that the Overall Job Satisfaction Scale (OJS; Brayfield \& Rothe, 1951) is more affectively based than the Minnesota Satisfaction Questionnaire (MSQ; D. J. Weiss, Dawis, England, \& Lofquist, 1967) and the MSQ is more cognitively based than the OJS. Other outcomes, such as rating of performance, are not explicitly discussed as an attitude or perception. However, like leadership measures, ratings of performance (e.g., task performance, organizational citizenship behvaior and counterproductive work behavior) require either the leader or follower to evaluate and judge some aspect of their own, or others' behavior.

Some outcomes seem intuitively easy to distinguish as affective, cognitive or behavioral. For example, affective organizational commitment is defined as "an affective or emotional attachment to the organization such that the strongly committed individual identifies with, is involved in, and enjoys membership in, the organization" (Allen \& Meyer, 1990, p. 2). This definition implies an affective attitudinal component and the items seem to reflect this by focusing on employees' feelings about the organization (e.g., I feel a strong sense of belonging to my organization). Therefore, according to the correspondence hypothesis, affective organizational commitment should be more strongly related to an affective component of a leadership perception.

One of the most commonly measured outcomes associated with leadership is follower performance. One might assume that performance represents a behavioral component of an attitude as it relates to the task performed by an individual. In the case of citizenship behavior (OCB), for example, it relates to whether or not individual perform acts such as helping others or not taking undeserved breaks (e.g., Williams \& Anderson, 1991). When such scales are selfrated and respondents are rating their own behavior measures of performance do reflect the behavioral component. However, it is often the case that leaders are asked to rate their followers' behavior. When this is the case such performance measures reflect a cognitive 
attitudinal component as they are concerned with perceptions of another person's behavior. It is beyond the scope of this paper to provide a comprehensive analysis of the content of leadership outcomes, but it is interesting to highlight that the majority of outcomes (except objective performance) reflect perceptions and thus can also be evaluated as attitudinal.

\subsection{Relationship between affective and cognitive components}

In the above sections we considered the three attitudinal dimensions as individual components when, in fact, they are likely to relate to each other. In this section we consider three aspects of the relationship between the attitudinal components that have been examined in the attitudes area that have relevance for understanding leadership perceptions.

The first aspect we examine concerns the consistency between affect and cognitive components of attitudes (ACC: affect cognitive consistency). A great deal of evidence supports the proposition that the affective and cognitive components of an attitude object are sometimes inconsistent (e.g., Cacioppo, Gardner, \& Berntson, 1997; Hochschild, 1981; Thompson, Zanna, \& Griffin, 1995; Zaller, 1992). Meta-analytic evidence also supports the contention that ACC moderates the link between attitudes and behavior (Kraus, 1995). Job satisfaction research has demonstrated the importance of considering ACC in relation to the relationship between job satisfaction and job performance (Schleicher et al., 2004); with those employees higher in ACC showing a significantly larger correlation between job satisfaction and job performance. Such findings can be applied to leadership perceptions and highlight the importance of knowing whether a measure is cognitive-based or affective-based and if there is consistency between attitudes. These findings demonstrate the importance of understanding the contribution of affective versus cognitive components of the leadership attitudes that people develop.

The second aspect concerns the role of primacy effects between affect vs. cognitive attitudinal components on attitudinal evaluations (e.g., Edwards, 1990; Edwards \& von Hippel, 1995). This primacy effect refers to the sequence of affect and cognition in an attitude's formation and has been shown, for example, to be an important determinant of its subsequent 
resistance to affective and cognitive means of persuasion (e.g., Edwards, 1990). This is particularly pertinent to the study of leadership as research has shown the importance of liking in the early stages of leader-follower relationship development and its role as a precursor of leadership ratings (Engle \& Lord, 1997; Lewter \& Lord, 1992; Liden, Wayne, \& Stilwell, 1993; Wayne \& Ferris, 1990). Liden et al. (1993), for instance, showed that liking assessed during the first two weeks of a leader-follower relationship predicted followers' ratings of the relationship six months later. This suggests that the initial basis for attitudinal evaluations can affect the interpretation of future attitude-relevant information.

The third aspect concerns the fact that the influence of affective, cognitive and behavioral components on overall attitudinal evaluations can vary across both between individuals and attitude objects (e.g., Eagly, Mladinic, \& Otto, 1994; Esses et al., 1993; Haddock, Zanna, \& Esses., 1993). Some individuals, across a wide range of attitude objects, possess attitudes that are largely consistent with either their affective or cognitive responses. Other individuals base their attitudes on both their affective feelings and cognitive beliefs equally or to a greater or lesser extent (Huskinson \& Haddock, 2004). Thus, affective and cognitive components are relied upon to different extents across individuals. A number of studies have shown that differences in affective and cognitive underpinnings of attitudes are related to individual differences in the motivational disposition of need for affect (e.g., Haddock, Maio, Arnold, \& Huskinson, 2008; Huskinson \& Haddock, 2004; Maio \& Esses, 2001) and need for cognition (e.g., Cacioppo, Petty, Feinstein, \& Jarvis, 1996; Haddock et al. 2008).

\section{Attitude structure}

Another key theme in attitude research is the investigation of the underlying structure of attitudes. Much of this work has been carried out under the theme of attitude strength because differences in the underlying structure of attitudes are thought to produce differences in the strength of the attitude. Therefore, as well as paying attention to the content of leadership 
attitudes, leadership research can benefit from an appreciation of the structure and strength of leadership attitudes.

\subsection{Facets of attitude strength}

When measuring leadership perceptions, researchers examine the valence (direction) and the extremity (where they lie on the continuum from positive to negative) of follower's attitudes. So, for example, the authentic leadership measure examines the extent that followers evaluate their leader as being authentic (low vs. high). Focusing purely on the valence of leadership attitudes is limited as it fails to account for other facets of attitudes that determine the strength of that attitude. Indeed, there are a number of qualities of an attitude that, independent of the valence of the attitude, reflect the strength of an attitude and consequently determine the extent that the attitude is consequential (Fazio, 1986). Research recognizes that “...the underlying attitudes of two individuals with identical scale scores may differ in many other respects that may affect the relation of the attitude score to the behavior manifested by those individuals" (Fazio \& Zanna, 1978, p. 399). These qualities have garnered a large body of research, producing an increasingly complex understanding of the factors that predict when attitudes are consequential and when they are not. ACC, as described above, is an example of a facet of attitude strength; other dimensions include: accessibility, ambivalence, extremity and importance and all relate to the broader concept of attitude strength. Table 3 provides a brief description of the facets of attitude strength.

\section{Insert Table 3 About Here}

As can be seen in Table 3, some of the features related to attitude strength reflect inherently subjective perceptions of the attitude-holder. For instance, attitude importance is a personal judgment of significance, reflecting the degree to which a person cares deeply about the attitude and is motivated to protect, express, and to be faithful to it in action. Similarly, attitude certainty is another subjective judgment, related to a subjective sense of the justification for holding a particular attitude. Attitude strength dimensions that rely on 
subjective judgement are well suited to measurement in surveys (see Krosnick \& Abelson, 1991) and thus can be easily incorporated into research designs that are frequently used to examine leadership. Other attitude strength dimensions may be harder to measure subjectively as they reflect the content and structure of representations stored in long-term memory. Attitude accessibility signifies the nature of the relation between an object's representation and its evaluation stored in memory, which controls the speed and ease with which the attitude comes to mind upon encountering the object. In Fazio's (1995) research, response latency has been employed as an index of attitude accessibility, which is thought of as being a good indicator of attitude strength, in part because accessible attitudes are more likely to be activated automatically on exposure to the attitude object than inaccessible attitudes. Due to its automatic activation, attitude accessibility is closely related to the concept of implicit attitudes. Many scholars have recognized that values, attitudes, and goals operate at implicit levels (Bargh \& Chartrand, 1999; Carver \& Scheier, 1998; Greenwald \& Banaji, 1995), occurring outside of people's awareness, intention, and control (De Houwer \& Moors, 2007). Thus the more accessible one's attitude, the more likely it will be automatically activated in the presence of the attitude object. In recent years a great deal of attention has been paid to the role of implicit attitudes. Implicit attitudes have been shown to have powerful effects on people's cognitions and behaviors (e.g., Greenwald, Smith, Sriram, Bar-Anan, \& Nosek, 2009).

\subsection{Consequences of attitude strength}

A large literature now exists documenting the relations of the attitude attributes with the four defining features of strong attitudes (i.e., resistance to change, stability over time, and a powerful impact on thought and on behavior; Krosnick \& Petty, 1995). These four features will be discussed in more detail below.

\subsection{Information Processing}

It has long been understood that attitudes can have profound effects on perceivers' judgments of their social world (Olson \& Zanna, 1993). Attitude scholars contend that attitudes 
can influence every step of the information-processing sequence, including attention, encoding, comprehension, interpretation, elaboration, and memory (e.g., Eagly \& Chaiken 1993; Fazio 1990; Hamilton et al 1990; Kunda, 1990). A central tenet of the theory of cognitive dissonance (Festinger, 1957) is that people are motivated to maintain consistency of their cognitive structure. Because cognitive inconsistency is aversive (e.g., Jonas, Diehl, \& Brömer, 1997; Maio, Bell, \& Esses, 1996; Nordgren, van Harreveld, \& van der Pligt, 2006) it is argued that people predominantly seek out and pay close attention to new information that confirms their existing attitudes and avoid information that might contradict their attitudes (see meta-analysis by Hart et al., 2009). This preference for supportive information over opposing information has traditionally been termed 'selective exposure' and as a 'confirmation bias' (Jonas, SchulzHardt, Frey, \& Thelen, 2001). A number of studies have demonstrated that stronger attitudes produce more pronounced selective exposure effects (e.g., Brannon, Tagler, \& Eagly, 2007; Holbrook, Berent, Krosnick, Visser, \& Boninger, 2005; Holton \& Pyszczynski, 1989). Research also shows that people overrate the quality of the justification that they can provide for their positions on topics; especially when they have strong attitudes (Fisher \& Keil, 2014).

Research demonstrating that strong attitudes impact information can have important implications for the study of leadership. It suggests that attitudes towards one's leader can impact on the information processing of followers, particularly when their attitudes are strong. The idea that leadership perceptions can influence followers information processing is not a novel one. The categorization theory developed by Lord, Foti, and Phillips (1982) theorized how perception as a leader and the content of generic leadership categories biases ratings of past behavior, affects behavioral expectations for the target stimuli, and may even define appropriate behavior for the stimuli.

This work has spurred more recent research related to implicit leadership theories (ILTs). ILTs represent cognitive structures or schemas specifying traits and behaviors that followers expect from leaders (e.g., Epitropaki \& Martin, 2004). These representations are 
unconsciously held by followers and help to distinguish 'leaders' from 'non-leaders' as they are activated when followers interact with a person in a leadership position (Kenney, SchwartzKenney, \& Blascovich, 1996; Shondrick \& Lord, 2010). Research has examined how the match between an employees' implicit leader profile and their actual leader's characteristics influences outcomes including the quality of LMX employee outcomes, such as organizational commitment, job satisfaction, and well-being (Epitropaki \& Martin, 2005).

ILTs focus on an individual's general beliefs about what characterizes a leader and does not represent a specific implicit attitude about one's actual leader. This work typically examines how ILTs contribute to the development of leadership perceptions. When followers develop strong attitudes about their leaders the work described above suggests followers might, for example, selectively pay attention to, or remember information about their leader that fits with their attitude. Thus, for instance, followers who strongly perceive their leader as 'authentic' may selectively ignore inconsistent information about their leader such as a failure to share information or admit mistakes. Thus considering leadership perceptions as attitudes extends work related to ILTs by encouraging an investigation into the consequences of the attitudes, once formed, in terms of information processing.

Interestingly, attitudinal ambivalence can have differing effects on the processing of attitude-relevant information. Some research shows that ambivalent respondents use more effort and deliberation in processing information, due to the motivation to seek out and scrutinize any information that can resolve the tension, than do respondents low in ambivalence (Brömer, 1998; Jonas et al., 1997; Maio et al., 1996; Nordgren et al. 2006). This suggests that one way for leaders to create attitude change in their followers is to first try to create attitudinal ambivalence.

\subsection{Resistance to Counter-Attitudinal Persuasion}

People are believed to be motivated to resist counter-attitudinal persuasion (i.e., influence designed to change their attitude) in order to hold 'correct' attitudes, restore freedom, 
or maintain psychological consistency and sense of control (Wegener, Petty, Smoak, \& Fabrigar, 2004). This reflects similar motivations that influence the selective processing of attitudinal relevant information discussed above. Indeed, resistance to persuasion is equally influenced by the strength of the attitude that is under attack from persuasive messages. Research demonstrates that strong attitudes show greater resistance to persuasion (e.g., Fazio, 1995; Tormala \& Petty, 2002; Zuwerink \& Devine, 1996). Attitudes that are ambivalent, for example, are more pliable in the face of a persuasive communication (Armitage, \& Conner, 2000).

The role of attitude strength in the persuasion process is important to consider with respect to leadership perceptions. Persuasion is an inherent part of a leader's role. To be effective leaders must persuade followers that they are trustworthy and competent. Transformational leaders, for example, aim to change their followers' attitudes, values, and beliefs to align them with those of the organization and guide their followers towards selfdevelopment and improved accomplishments (Bass, 1998). Transactional leaders, in contrast, guide followers based on a system of reward and punishment. Various influence tactics used by transformational and transactional leaders have been identified, including: rational persuasion, inspirational appeals, consultation, personal appeals, exchange, legitimating tactics, pressure, and coalition tactics (Epitropaki \& Martin, 2013; Yukl, 2002; Yukl \& Seifert, 2002). However, the research discussed above suggests that leader persuasion attempts may be less impactful when their followers hold strong leadership attitudes. When this is the case followers are more likely to resist persuasive appeals and continue holding the same leader attitudes. In other words it may be difficult for leaders to alter their follower's attitudes towards them. This also has implications for leadership development programs that are designed to change leader's behaviors in order to improve leadership and followers attitudes towards that leader. Such programs might benefit from paying attitude to research related to attitude change and the best way to persuade those holding strong attitudes to change. 
Furthermore, research has revealed that individual differences in attitude structure are differentially influenced by persuasion that is affect-based or cognitive-based. Affect-based persuasion attempts to highlight a positive affective response associated with the attitude object, whereas cognitive-based persuasion focuses on the attributes associated with the object (e.g., Haddock et al., 2008). Indeed, persuasion researchers have often reported a matching effect, where the message that targets the individual's attitudinal basis directly is more persuasive than the message that does not (e.g., Huskinson \& Haddock, 2004; Haddock et al., 2008). Specifically, affective appeals are more influential among affect-based compared to cognition-based attitudes, and that cognition-based attitudes are more influenced by cognitive than affective information. Again such findings have implications for leadership as it suggests that the way leaders try to persuade followers should match the content of the follower's attitude. It is clear that liking plays a powerful role in the early development of leader-follower relationships (Liden et al., 1993) and it is probable that for many followers leader-follower attitudes may be based on affect. In such cases leaders may be more persuasive if they make persuasive appeals rather than rational, cognitively-based appeals.

\subsection{Persistence over time}

It is highly likely that attitudes that resist counter-persuasion are subject to biased information processing, are more likely to persist over time and thus show high levels of stability. Thus, research demonstrates that strong attitudes are more stable over time (e.g., Bassili, 1996; Swann, Pelham, \& Chidester, 1988; Visser, Bizer, \& Krosnick, 2006; Zuwerink \& Devine, 1996). The question of attitude stability is an important one as scholars have questioned whether attitudes should be conceptualized as mentally represented summary evaluations that can be retrieved from memory or, alternatively, as temporary constructions. According to the attitudes-as-temporary-constructions approach, attitudes are construed 'on the spot' on the basis of temporarily accessible pieces of knowledge (Wilson \& Hodges, 1992; Schwarz, 2000; Schwarz \& Bohner, 2001). Researchers favoring a construal view on attitudes 
are sceptical with regard to the impact of attitudes on behavior and argue that attitudes are mainly context dependent and therefore not stable over time (e.g., Schwarz, 2000; Schwarz \& Bohner, 2001). Holland, Verplanken, and Van Knippenberg (2002) suggest these views can be reconciled through consideration of attitude strength, suggesting that strong attitudes are more stable and likely to be retrieved from memory, whereas weak attitudes may be construed onthe-spot.

The stability of attitudes is pertinent to leadership research that has paid relatively little attention to the development and stability of followers' leadership perceptions. For example, with regards to leader-member relationships, it is important to understand how the relationship develops from the initial interaction through to the later stages of the relationship (Liden et al., 1993) but also how stable these relationships are once established. To date, relatively little is known about how the relationships develop and are maintained over time. The few studies that have measured LMX (in)stability have revealed that the relationship tends to be relatively stable over time, with correlations ranging from .41 to .72 (Bauer \& Green, 1996; Liden et al., 1993; Nahrgang, Morgeson, \& Ilies 2009; Volmer, Niessen, Spurk, Linz, \& Abele, 2011). Similar correlations have been reported in regards to the stability of transformational leadership (e.g., Bommer, Rich, \& Rubin, 2005). Given the lack of research attention related to the stability of leadership perceptions, the role of attitude strength in determining stability is of particular interest to our current understanding of leadership.

Scholars have emphasized that in order to build useful theories of organizational behavior discerning the rate of change in constructs is vital (George \& Jones, 2000). In order for leaders to be effective it is important to understand the stability of follower's perceptions. If such perceptions are characterized by instability then it highlights the need for leaders to pay attention to the maintenance of how they are perceived. Attitude theory would suggest that if a follower has formed a strong attitude about their leader it may be stable because, for example, they focus their attention on attitude congruent information. This might suggest that if, for 
example, followers strongly perceive their leader as transformational then they will likely maintain this perception over time. This also has implications for leaders who may find it difficult to change a follower's attitude when it has been formed.

\subsection{Prediction of behavior}

In many ways the utility of the examining leadership perceptions as an attitude rests on the assumption that attitudes influence behavior. Positive attitudes should predispose approach tendencies whereas negative attitudes should predispose avoidance tendencies (Ajzen \& Fishbein, 2000). The same is true of leadership theories that suggest that leadership styles should motivate follower behaviors (such as performance). However, over many years of attitude research, this basic proposition has been challenged by findings showing that on many occasions attitudes are not good predictors of behavior (e.g., Ajzen, 1988; Leippe \& Elkin, 1987; Wicker, 1969). In fact, it appears that there is considerable variability in the degree that attitudes predict behavior (Ajzen, 2000). Similar findings have been shown in leadership research that shows a high degree of variability between measures of leadership and employee behavior such as task performance and OCB. Transformational leadership, for example, is typically correlated with followers' job performance (e.g., Judge \& Piccolo, 2004), but inconsistent effects have emerged in both field studies and laboratory experiments (Barling, Weber, \& Kelloway, 1996; Bono \& Judge, 2003; Dvir, Eden, Avolio, \& Shamir, 2002; Kirkpatrick \& Locke, 1996). Similar findings are shown with respect to the relationship between LMX and work outcomes such as OCB; some studies report a negative relationship between the two variables (e.g., Loi \& Ngo, 2009) with others reporting non-significant (e.g., Wat \& Shaffer, 2005), weak positive (e.g., Bernerth, Armenakis, Feild, Giles, \& Walker. 2007) and strong positive (e.g., Henderson, Wayne, Shore, Bommer, \& Tetrick, 2008) associations.

In order to address the inconsistent results between attitudes and behaviors, researchers have responded by elucidating the conditions that enhance or reduce consistency between attitudes and behaviors; providing a much clearer understanding of both how and when 
attitudes predict behavior (e.g., Lord et al., 1991). Such understanding may be helpful in informing leadership research by specifying when and how leadership attitude can lead to employee behavioral outcomes. Two seminal theories explaining the link between attitude and behavior are the theory of reasoned action (Ajzen \& Fishbein, 1980; Fishbein, 1967; Fishbein \& Ajzen, 1975) and its expanded version, the theory of planned behavior (TPB; Ajzen, 1988, 1991). TPB asserts that behavior is directed by one's attitude and two other considerations: beliefs about the normative expectations of others and beliefs about the presence of factors that may foster or obstruct performance of the behavior. The normative beliefs result in perceived social pressure or subjective norms; and control beliefs give rise to perceived behavioral control, the perceived ease or difficulty of performing the behavior. Broadly speaking the theory suggests that a more favorable attitude, stronger subjective norms, and greater perceived control should create stronger intentions to perform a related behavior.

TPB has received considerable attention in the literature and has been used to understand a wide range of behaviors, such as health behaviors (e.g., McEachan, Conner, Taylor, \& Lawton, 2011), driving safety (e.g., Elliott, Armitage, \& Baughan, 2003) and ethical decision-making (e.g. Buchan, 2005). The model has had some application in the organizational behavior domain, for example, as a framework to examine the development of turnover intentions and later voluntary turnover (Van Breukelen, Van der Vlist, \& Steensma, 2004) and intentions to support organizational change (Jimmieson, Peach, \& White, 2008). The framework has not been utilized to explain how leadership attitudes lead to behavioral intentions and behavior. Research has investigated the role of leadership perceptions in the development of follower intentions to engage in various behaviors. For example, transformational leadership has been shown to lead to increased feedback-seeking intention (Levy, Cober, \& Miller, 2002), whilst perceptions of leader integrity is associated with lower intentions to commit unethical acts (Peterson, 2003). Various leadership perceptions have been associated with followers intention to quit the organization, such as LMX (e.g. Harris, 
Wheeler, \& Kacmar, 2009), abusive supervision (e.g., Khan, Qureshi, \& Ahmad, 2010), and servant leadership (Jaramillo, Grisaffe, Chonko, \& Roberts, 2009). However, although there is evidence that leadership attitudes do lead to the development of behavioral intentions; studies have not included leadership attitudes within the wider TPB framework. Interesting, the role of self-efficacy, which shares many similarities with the concept of perceived behavioral control is often investigated as a mediator between leadership perceptions (e.g., Gong, Huang, \& Farh, 2009; Hu, \& Liden, 2013; Pillai, \& Williams, 2004) and outcomes, as opposed to the way it is factored into the TPB framework as an additional antecedent.

Attitude strength has been consistently shown to moderate the attitude-intention and attitude-behavior link (e.g., Connor, Povey, Sparks, James, \& Shepherd, 2003; Cooke \& Sheeran, 2004). Research in the organizational behavior domain, for example, has demonstrated that job attitude strength moderates the relationship between job satisfaction and several criteria of interest to organizational behavior researchers (job performance, organizational citizenship behavior, withdrawal; Schleicher, Smith, Casper, Watt, \& Greguras, 2015). Focusing specifically on ACC, Schleicher, et al. (2004) demonstrated the moderating effect it had on the job satisfaction-job performance relationship, with those employees high in ACC showing a significantly larger correlation between job satisfaction and performance than those low in ACC. Similarly, research shows that job ambivalence (i.e., the coexistence of positive and negative job evaluations) moderates the job satisfaction-OCB relationship (Ziegler, Schlett, Casel, \& Diehl, 2012).

In fact, a wealth of research demonstrates that attitude strength moderates the attitudebehavior link. Thus, applying theory related to attitude strength to leadership attitudes has great potential to extend our understanding of when leadership attitudes will influence followers' thoughts and behaviors. This would involve investigating not just the extent that followers hold positive or negative attitudes about their leader but also examining whether or not these attitudes are certain, importance or ambivalent. For instance, LMX theory, has considered the 
relationship to exist on a continuum from low to high quality (Martin, Epitropaki, Thomas, \& Topakas, 2010). However, regardless of the overall quality, leader-follower relationships may be comprised of an array of positive and negative evaluations. Thus, for example, high-quality LMX may be accompanied by both positive (e.g., enjoy the company of the manager) and negative aspects (e.g., not receiving enough task feedback). Measures of relationship attitudes, developed in social psychology and the relationship science literatures, similarly suggest that unidimensional measures fail to address the complexity of relationships satisfactorily. Accordingly authors have developed scales where it is possible for a relationship to be high on positive relationship qualities, high on negative relationship qualities, high on both positive and negative relationship qualities, or high on neither (e.g., Mattson, Paldino, Johnson, 2007). Such measurement can therefore capture various types of relationship attitudes, including those characterized by ambivalence. Considering ambivalence in leader-follower relationships could allow researchers to gain a far greater understanding of when leader-follower relationship will be more impactful.

In two separate studies recent research has utilized two aspects of attitudes strength (importance and ambivalence) to investigate the relationship between LMX and performance and OCB. The findings of this work shows that LMX attitude importance moderates the relationship between LMX and OCB, mediated by the degree that followers felt obligated towards their leader (Lee, Martin, Thomas, \& Guillaume, under review). An additional study demonstrated that LMX attitude ambivalence (measured as a subjective evaluation) had a negative effect on task performance, independent of overall LMX quality (Lee, Thomas, Martin, \& Guillaume, under review). This negative effect was shown to be mediated by negative affect that resulted from holding an ambivalent, inconsistent attitude about one's leader.

In summary, one of the central goals of attitude research has been to explain both how and when an attitude predicts behavior. A great deal of research and theory now exists to 
provide confidence that in many instances attitudes are a good predictor of subsequent action. Given that one of the main goals of leadership research has been to link leadership perception to work behaviors such as task performance and $\mathrm{OCB}$, it seems prudent for future research to utilize attitude research to extend understanding of this link. Frameworks such as attitude strength and TPB may be particular useful in this endeavour.

\subsection{Implicit attitudes and behavior}

The theories of reasoned action and planned behavior, discussed above, are predicated on the notion that human social behavior is reasoned, controlled, and in some way planned. $\mathrm{TPB}$, for instance, assumes that before acting individuals take account of the possible consequences, the normative expectations of significant referents and factors that may obstruct the performance of such action. Thus according to the TPB, leadership attitudes should influence employee's actions in a deliberate and planned way. Although these models do not necessarily imply a deliberate, effortful retrieval of such information prior to every behavior, these perspective have been challenged by many theorists who argue that human behavior is often automatic, mindless, or habitual (e.g., Aarts, Verplanken, \& van Knippenberg, 1998; Fazio, 1990; Triandis, 1977). Indeed, evidence has accumulated highlighting the fact that many behaviors are driven by unconscious processes. These processes are intuitive, spontaneous and unintentional (e.g., Bargh, 1994; Wilson, 2002) and therefore are not captured through traditional self-report attitude scales. Research has demonstrated that such attitudes, when activated, can have powerful effects on behavior, showing that human action can often be initiated automatically (e.g., Swanson, Swanson, \& Greenwald, 2001). Examples of such automated action include, the fact that implicitly activated achievement goals elicit higher levels of job performance (Shantz \& Latham, 2009), and implicitly activating imagery related to business (e.g., briefcases) leads to diminished cooperation in economic games (Kay, Wheeler, Bargh, \& Ross, 2004). 
The consideration of automatic processes has led scholars to posit dual process models of attitudes (e.g. Fazio, 1990; Petty, \& Cacioppo, 1986; Wilson, Lindsey, \& Schooler, 2000). Such models highlight the difference between automatic versus controlled information processing. For example, it has been suggested that there are two distinct processes or modes by which attitudes can influence behavior (e.g., the Motivation and Opportunity as Determinants model (MODE); Fazio, 1990). The MODE model suggests that when the individual is highly motivated and capable of thinking in a controlled manner, behavior is held to be thoughtfully planned, based on one's attitudes toward the behavior. However, where motivation or opportunity for controlled information processing is lacking, attitudes are held to impact on behavior in a more automatic manner. For attitudes to guide behavior in this spontaneous manner, attitudes must be automatically activated in the presence of the attitude object. Attitudes will fail to predict behavior when the behavior is enacted under conditions that do not lead to deliberative processing of the attitude or its automatic activation.

The distinction between automatic and controlled information processing highlights the importance of automatically activated attitudes. However, despite their potential application, implicit measures have received relatively modest attention within the organizational literatures, largely owing to the fact that they are more difficult to measure (Uhlmann et al., 2012). However, there has been a recent surge in the number of studies using implicit measures to understand a number of phenomenon, including traits (e.g., Johnson, Tolentino, Rodopman, \& Cho, 2010; Johnson, \& Saboe, 2011), attitudes (e.g., Johnson \& Lord, 2010), and values (e.g., Reynolds, Leavitt, \& Decelles, 2010). Leadership researchers have also realized the potential that implicit attitudes can have on the leadership process. Implicit measures may help determine a person's unconscious attitude towards their leader. Use of implicit measures may, in fact, be critical to our understanding of leadership as such measures are particularly informative when participants are unwilling to admit their attitudes to others, or even to themselves (Uhlmann et al., 2012). As such implicit measures have been shown to resist 
attempts at deliberate faking (e.g., LeBreton, Barksdale, Robin, \& James, 2007). This makes implicit attitudes especially useful in situations where evaluation apprehension is likely, such as measuring satisfaction with one's job or supervisor in a study sponsored by the organization (Leavitt, Fong, \& Greenwald, 2011).

Leavitt et al. (2011) has demonstrated the use of implicit measures of various facets of job satisfaction, demonstrating that such methods can be applied to leadership. The study examined how implicit attitudes regarding the organization, supervisor, and coworkers combined with explicit job satisfaction measures to predict job performance. Interestingly the results showed that implicit satisfaction with one's organization and coworkers predicted both job performance and OCB, respectively, above that explained by explicit attitudes. However, contrary to the authors' predictions, implicit attitudes towards one's supervisor did not predict these outcomes (Leavitt et al., 2011). These results are somewhat surprising given the strong links between leadership attitudes and performance outcomes. Whether or not this is indicative of a differential effect of implicit and explicit leadership attitudes is uncertain given this is the only study to measure leadership in this way.

Future work should continue to consider implicit attitudes towards leadership, how they impact employee outcomes, and to what extent they differ from explicit measures of leadership attitude. Future research can also move beyond implicit measures of supervisor satisfaction to look at implicit attitudes towards different aspects of leadership. For example, research could examine implicit attitudes towards one's leader-follower relationship and how this compares with explicit relationship attitude. Research in the interpersonal relationships area has developed ways of measuring implicit attitude specific to aspects of romantic relationships (e.g., Baccus, Baldwin, \& Packer, 2004; Banse \& Kowalick, 2007; LeBel \& Gawronski, 2009; Zayas \& Shoda, 2005). Such measures could be adapted to focus on capturing implicit attitudes towards the leader-follower relationship. 
As well as playing a moderating role in the link between explicit attitudes and behaviors, attitude strength also influences the impact of implicit attitudes. As mentioned previously, the more accessible an attitude is in memory (an indication of attitude strength) the greater impact that attitude will have on automatic activation of that attitude and thus will be more likely to guide the effects of implicit attitudes. Indeed, when measuring implicit attitudes one is assessing attitude accessibility. Research also suggests that the importance of one's attitude moderates the relationship between implicit and explicit attitudes (Karpinski, Steinman, \& Hilton, 2005). This again highlights the advantage of considering facets of leadership attitudes, such as importance, in order to better predict when leadership will influence behavior.

\section{Attitude function}

The previous sections have highlighted the fact that attitudes are a multifaceted phenomenon and considering their complexities is important in understanding when they will be more or less impactful on information processing and behavior. However, it is also important to understand that individuals hold attitudes for a variety of reasons. Individuals, for example, may support a sports team in order to fit in with one's relatives and friends supporting the same team. In contrast, attitudes toward abortion might be based on the value an individual places on freedom of choice or the sanctity of life. Such differences in the motivational bases of attitudes relates to the needs or functions that are fulfilled by holding certain attitudes. Thus, the functional approach to attitudes posits that attitudes fulfil psychological needs for the individual (Olson \& Zanna, 1993). Similarly leadership research has tried to understand how leaders fulfil the basic needs of their followers (e.g., Hetland, Hetland, Schou, Andreassen, Pallesen, \& Notelaers, 2011). Such work tends to focus on the basic psychological needs for autonomy, competence, and relatedness (Kovjanic, Schuh, Jonas, Quaquebeke, \& Dick, 2012). Theories of attitude function, however, address the issue of 'why' individuals hold the attitudes they do. Attitude function has gained prominence in the attitude 
literature due to interest in understanding the reasons people hold particular attitudes and the implications of holding attitudes that fulfil different functions. Seminal theories of attitude function were developed several decades ago, but are still hugely influential (Katz, 1960; Smith, Bruner, \& White, 1956). Shavitt (1990) grouped the attitude functions proposed in these theories into three distinct categories: utilitarian, social identity, and self-esteem maintenance.

The utilitarian function focuses on the role of attitudes in maintaining rewards. As such, utilitarian attitudes operate in a way that maximizes the rewards and minimizes the punishments obtained from objects in one's environment. Part of this process involves summarizing the outcomes intrinsically associated with objects and guiding behavior that obtains the benefits associated with the objects (Katz, 1960). For example, a person's attitude toward a mobile phone might be based on the intrinsic rewards (e.g., increased amount of applications) and punishments (e.g., reduced battery life) obtained from such products. These attitudes are likely to guide behaviors that maximize the phone's rewards and minimize its punishments (e.g., carry a spare battery charger). This utilitarian function is highly relevant to research related to leadership attitudes. A follower may well hold an attitude about their leader in order to maximize their own interest and rewards received from the leader. Indeed, this type of function would be highly expected with regards to leadership as leaders will almost certainly hold the power to reward and punish their followers (e.g., Judge \& Piccolo, 2004; Podsakoff, Bommer, Podsakoff, \& MacKenzie, 2006). Leadership attitudes that fulfil a utilitarian function should guide follower behavior in ways that lead to rewards and decrease the likelihood of punishments.

Another attitude function that may be particularly pertinent to the study of leadership is the social-identity function that may be fulfilled by certain attitudes. Attitudes that have a social-identity function (Shavitt, 1990) help individuals identify with people whom they like and to distance themselves from people whom they dislike. This function may help explain how some followers come to form attitudes about their leader. In some cases, particular leader 
attitudes may form based on other employees in the work group and a desire to fit in with other people in the group. LMX research, for example, has emphasized the existence of leader ingroups and out-groups that develop in work teams (Dansereau, Cashman, \& Graen, 1973). Followers may base their attitudes towards the leader on the attitudes of one of these subgroups, perhaps based on which group they identify with. Thus, the negativity or positivity of attitudes toward leadership may depend on whether the attitude fulfils social-adjustive concerns. In other words, it may be seen as popular to dislike or like ones leader as holding this attitude might help one be accepted and adjust in a group whose members have similar views of the leader; perhaps fulfilling a need to belong.

One of the best examples of the use of social identity function in leadership is the social identity theory of leadership which has been developed principally by Hogg, van Knippenberg and colleagues (Hogg, 2001; Hogg \& van Knippenberg, 2003; Hogg, van Knippenberg \& Rast, 2012; for empirical overviews see Ellemers, de Gilder, \& Haslam, 2004). This is a social cognitive approach that proposes that effective leaders are highly group prototypical, i.e., they embody the desirable characteristics and behaviors of group members and therefore are in a position to influence group members. Prototypical leaders are more central and important to self-definition than non-prototypical leaders because they embody group norms and are more likely to favor the in-group and promote the well-being of the group. Numerous studies have shown that prototypical leaders are perceived as more desirable and effective than non-prototypical leaders (see Hogg et al., 2012, for a review). Of relevance here is that the approach shows the importance of identifying with a leader who represents the desirable aspects of the team. Through this identification processes, team members feel a sense of worth, higher self-esteem and positive well-being.

Some people develop attitudes based on their values, which are abstract ideas that people consider to be important guiding principles in their life (Schwartz, 1996). One function that attitudes can fulfil is a value expressive function (Katz, 1960) and this function exists 
when people adopt a particular attitude in order to be consistent with specific values. The importance of values has been examined in leadership research. Research, for example, has shown that individuals' prefer leaders with whom they perceive they share similar attributes and values (e.g., Ehrhart \& Klein, 2001). Jung and Avolio (2000) suggested that when follower's values are congruent with the transformational leader's values, they are expected to shift motivation from focusing on self-interests to considering the more collective interests of the group or organization. The authors demonstrated that transformational leadership had both direct and indirect effects on performance mediated, in part, through followers' value congruence. Other research has demonstrated that the quality of LMX is influenced by congruity between leader and member values (Ashkanasy \& O'Connor, 1997). Specifically the results showed that LMX quality is higher when leaders and members share achievement and obedience values. The importance of values in understanding the leadership process supports the idea that leadership attitudes may serve a value expressive function.

Recent research has also focused on when macro-contextual factors have an impact on attitude-value links (Boer \& Fischer, 2013). The authors showed, using meta-analytic techniques that cultural factors influenced the link between values and attitudes; showing that collectivism was associated with stronger attitude-value links for conservation values, individualism was associated with stronger attitude-value links for self-transcendence (vs. selfenhancement) values. Specifically, the findings show that self-transcendence-motivated (values that promote the welfare and the acceptance of close and distant others as equal) attitudes were more consistently guided by self-transcendence values with increasing societal individualism. The authors suggest that such individualistic societies emphasize context independence and personal values are more consistently linked to social attitudes with increasing context independence. In contrast, in more collectivistic settings, social attitudes are more consistently driven by conservation values compared to individualistic societies. These findings may have important implications for the study of cross-cultural leadership, which aims to understand 
cultural differences and potential barriers to effective leadership (e.g., Javidan, Dorfman, De Luque, \& House, 2006). Understanding how cultural values might impact the function of leadership attitudes can help to understand how leadership might differ across cultures and how, for example, leadership persuasive appeals should vary depending on the context. The initial research of Boer and Fischer (2013) seems to suggest that in individualistic cultures individuals show more cognitive consistency between their values and social attitudes, compared to collectivistic cultures (e.g., Suh, 2002). This suggests that leadership in this context might require a greater appreciation for the individual follower's values and how these might impact on the development of leadership attitudes. In contrast, leaders in more collectivist cultures may need to appreciate societal norms and how these may guide followers' leadership attitudes.

The final function that attitudes can serve, according to the classification of Shavitt (1990), refers to self-esteem maintenance. This function is served by attitudes that defend the self against internal conflict. For instance, a poor squash player might grow to dislike the game because it threatens his or her self-esteem. In the context of leadership attitudes this function may motivate followers to develop particular attitudes about their leader in a bid to protect their self-esteem. For example, attitudes that perform this function, it is argued, meet individuals' need to enhance or to maintain self-worth. To ascribe inferior status to another group may give individuals some sense of superiority. This has clear links to recent research related to LMX, which highlights that the subjective ratings by individuals of their LMX compared to the LMXs of coworkers (labelled 'LMX social comparison') explain unique and meaningful variance in outcomes beyond LMX and the actual standing of those individuals in the LMX distribution (Vidyarthi, Liden, Anand, Erdogan, \& Ghosh, 2010). This comparison process may be influenced by the function that leadership attitudes fulfil. For example, a follower who has an LMX attitude that is motivated by self-esteem maintenance may choose to engage in a downward social comparison (e.g., Major, Testa, \& Blysma, 1991), choosing to 
compare their relationship with a co-worker who is worse off in order to maintain feelings of self-esteem. Another example of how the self-esteem maintenance function may influence leadership perception is that a follower who is performing badly may develop an unfavorable attitude towards their leader in order to attribute their poor performance to a lack of leadership support.

The challenge for researchers in applying attitude functions to leadership (or indeed to any attitude object) lies in being able to determine what function an attitude serves. Knowing this information can help provide a clearer understanding of how and why an attitude is motivating the individual and guiding behavior. Furthermore, knowledge of attitude function would inform a leader as to the form of persuasion that is necessary to change follower attitudes. For example, if a follower's attitudes towards leadership are ostensibly motivated by utilitarian concern then leaders should appeal to the rewards and punishments that they can provide and make salient the behaviors that will maximize these rewards and minimize the punishments. Conversely followers whose leadership attitudes are fulfilling a social-identity function may respond better to group-based appeals. Thus, research on attitude function theory suggests that attitude change may occur through the closer match between an appeal and the attitude's primary function (Shavitt, 1990; Maio \& Olson, 1995). At the heart of this theory is the study of the motivational basis for an attitude and the need to understand how it can be changed (Eagly \& Chaiken, 1993).

The functions described above relate to the motives underlying the attitudes of an individual. At the heart of the functional approach is the central idea that people might like or dislike an attitude object with equal intensity but for completely different reasons. Attempts to change one's attitude might require different methods or appeals, depending on the function being served. In other words, the functional approach posits the notion that attitude change occurs when message and motive match (Katz 1960). Specifically attitude functional research has examined the effects of functionally matched messages (vs. not matched) on message 
persuasiveness (e.g., Petty, Wheeler, \& Bizer, 2000). This research shows that appeals about objects that predominantly engage a utilitarian function are more persuasive if they describe the object's features, whereas persuasive appeals about objects that predominantly engage a social identity function will be more effective if they focus on what the object communicates to others (Shavitt, 1990). This has substantial implications for understanding leadership and leaders attempts to persuade followers and change their attitudes. For instance a leadership attitude serving a utilitarian function is based upon principles of expected reward. As such leaders may have more influence over followers by focusing on addressing utilitarian needs such as highlighting the rewards associated with certain behaviors. A person holding an attitude toward a leader serving the value-expressive function, will likely be persuaded by appeals that tap into the underlying values that individual holds.

\section{Theoretical, methodological and practical implications.}

The aim of this review was to provide a theoretical basis for the examination of leadership perceptions within the framework of attitude theory. Given the size of the attitude literature we limited the scope of the review to some of the main themes within this body of work could inform our understanding of leadership perceptions. Specifically, we focused on how the content, structure and function of attitudes could apply to the formation of leadership perceptions and its impact on work outcomes. In our content analysis we highlighted that the majority of theories measure leadership perception as a cognitive evaluation, indicating a follower's thoughts about their leader. Far fewer items related to followers affective feelings towards their leader, whilst the behavioral component was seldom measured at all. Thus, our analysis suggests that the affective and behavioral components of leadership attitudes are being overlooked. This finding is particularly interesting with respect to the behavioral component as many leadership measures specifically aim to measure the leader's style of behavior. The components of leadership attitudes are important because, as demonstrated in the review, each component may have differential influences on outcomes. 
As well as considering the attitudinal content that forms the basis of attitudes, this review also emphasized that attitudes are comprised of an array of properties that determine the extent that attitudes impact information processing, resist counter-persuasion, persist over time and guide behavior. Paying attention to these facets, that determine the strength of an attitude, can extend understanding of when leadership perceptions are likely to influence work outcomes; elucidating some of the processes that might underlying these effects. Whereas attitude content and structure speaks to the value of understanding the basis of leadership perceptions (in terms of 'what and when'), considering attitude function emphasizes the underlying motives (in terms of 'why') that leadership perception fulfil. Leadership attitudes can realise various needs of followers and provide an opportunity for researchers to pay greater attention to how these attitudes are influenced both internally (e.g., by the persons values) and externally (e.g., by the social context).

Taken together the concepts of attitude content, structure and function provide a useful theoretical framework for leadership researchers to explore the nuances of leadership perceptions and how these relate to outcomes. We contend that doing so has myriad theoretical, methodological, and practical implications. On this basis of this review we discuss some of these implications below.

\subsection{Theoretical implications}

An overarching theme of this review is that it highlights the benefits of moving from a leader-centric approach towards examining leadership perceptions to an approach that considers leader perceptions as a property of both the leader and follower. A leader-centric approach assumes that leadership measurement accurately reflects the behaviors and styles of

the leaders themselves. Over the years scholars have emphasized that using follower reports of leader behavior suggests that behavioral ratings reflect not only recall of actual behaviors, but such perception are also influenced by many extraneous factors (e.g. Schriesheim \& Kerr, 1974; Schriesheim, Kinicki \& Schriesheim, 1979). Schriesheim et al. (1979), for example, 
showed the effects of leniency on follower ratings of leader behavior. Leniency refers to the tendency that persons describing someone they know and like are much more likely to attribute positive traits to them than negative traits. Recently, scholars have suggested that followers perceptions of leader behavior are also influenced by inferences based on semantic memory, which may vary between individuals (Hansbrough, Lord, \& Schyns, 2014). Similarly by considering leader perceptions as attitudes, this review has shown that such perception can be influenced by a host of attitudinal processes that may not accurately reflect leader behavior. Attitudes are, for instance, shaped by various content and motivations that influences information processing and the stability of such attitudes. Thus, this review shows that leadership perceptions are a property of both the leader's behavior and the follower's subjective interpretation of that behavior. Acknowledging the role of follower-centric processes in the formation and maintenance of leadership perceptions allows a consideration of a wide range of factors that can affect this interpretative process. We propose drawing upon an attitudes framework offers many insights into how these interpretation processes occurs.

Arguably the most important outcome of this review is that it proposes the need to consider leadership perceptions not only as an evaluation in terms of its valance and extremity (e.g., positive vs. negative, low vs. high), but to conceptualize it as a multi-faced attitude comprising of various dimensions. Considering the multi-dimensional nature of leadership perceptions gives insights into important features (such as, attitude importance and ambivalence) that can be hugely influential in determining the impact of such perceptions

Further, we propose that the application of an attitudes framework can provide a unifying approach to understanding the divergent leadership perspectives. As the content analyses of the leadership measures showed there is considerable variation both within and between different measures to the extent that they contain different attitudinal components. The use of an attitudes framework (specifically examining the tripartite components) gives an opportunity to assess the content of different leadership measures and why they might have 
different impacts with outcomes. A development of this logic is that the attitudes framework provides a basis for the development of future measures of leadership perceptions that contain all three attitudinal components (affect, cognition, and behavior).

While the role of content and structure examines the underlying architecture of leadership perceptions, the role of attitude functions focuses on the motivational processes that underlie leadership perceptions. More specifically, this highlights the reasons why people hold leadership perceptions, how these perceptions relate to their personal identities and ultimately how they impact upon outcomes. Of specific note, is the role of the social identity function that emphasizes that leadership perceptions are influenced by the social context determining the extent to which followers assimilate their attitudes to the group prototype (Hogg, 2001; Hogg et al., 2012). This highlights the broader benefits of adopting an attitude perceptive in enabling a wider appreciation of leadership perceptions that are not just affected by the follower-leader dyad but are socially construed within the wider social context. Thus, this allows for a crosslevel (i.e., individual, follower-leader dyad, team-level) analysis of leadership perceptions.

The use of an attitudes framework also has the potential to contribute to understanding the difference in leadership perceptions when assessed from the follower and leader perspectives (Sin, Nahrgang, Morgeson, 2009; Zhou \& Schriesheim, 2009, 2010). It might be the case, for example, that follower-leader congruence of leadership perceptions might be higher for different attitudinal components. For example, leader and follower perceptions that are both based on affect may be more convergent than when they are based on different attitudinal components. In this context it is important to consider methodologically how such studies are conducted as this might also contribute to incongruent perceptions from a follower and leader. Follower ratings of leadership perceptions typically focus on evaluating various aspects of the leader's behavior while the leader's perceptions, by contrast, typically measure the leader's perceptions of their own behavior. Thus, in many cases follower and leader perspectives might be assessing different attitudinal components. For example, consider the 
following item from the MLQ (MLQ, Bass \& Avolio, 1995), which assesses transformational leadership: 'Spends time teaching and coaching'. When this item is completed by the follower it assesses the cognitive component of the attitude but when completed by the leader ('I spend time teaching and coaching') it assesses the behavioral components of the attitude. Therefore, in many leadership measures changing the focus of the items (from the follower to the leader perspectives) also changes the attitudinal component that is assessed and this might contribute towards low levels of congruence in ratings. This point was highlighted recently by Schriesheim and Liu (2013), who demonstrated, using content assessment, that many of the LMX-7 (Graen \& Uhl-Bien, 1995) items measures different components of an attitude when rated by the leader, compared to when it is rated by the follower.

So far we have said relatively little about how different leadership styles are related to attitudes. We believe that research in attitudes is informative in this respect. According to the principle of compatibility attitudes predict behaviors to the extent that the attitude and behavior correspond in their action, target, context and time (Ajzen, 1988; Ajzen \& Fishbein, 2005; see also Fisher, 1980; Hulin, 1991). Operationalizing the attitude and behavior at the same level of specificity is therefore thought to increase the strength of the relationship between attitudes and behaviors. Indeed, Kraus (1995) showed in a meta-analysis that the correlation between attitudes and behaviors was larger when the principle of compatibility was followed than when it was not ( $r=.62$ vs. $r=.29$ ). Relatedly, general job attitudes were found to increase their predictive validity the more the outcome was defined in broader and more inclusive ways (e.g., in-role performance vs. individual effectiveness or people's tendency to contribute desirable inputs toward their work role) (Harrison et al., 2006). This might be taken to suggest that generic attitudes towards leadership (e.g., leader satisfaction) should have higher predictive validity when follower behavior is measured in more general terms (e.g., individual effectiveness), while specific attitudes towards leadership (e.g., LMX, ethical leadership, authentic leadership) should be more predictive of specific follower behaviors (e.g., 
cooperative, ethical, and voice behaviors). Integrating research in attitudes with research in leadership might therefore aid in identifying which leadership style is most predictive for certain types of follower behaviors but also respond to calls to develop more clearly defined and empirically distinct aspects of leadership (e.g., van Knippenberg \& Sitkin, 2013). Future research might, therefore, categorize existing leadership scales and outcomes in terms of action, target, context and time or develop new measures that take into account such a categorization.

\subsection{Methodological implications}

As discussed above, this review identifies many theoretical benefits associated with the integration of attitude theory and leadership perceptions. Such cross-fertilisation is only possible with careful alignment of measurement and methodological approaches if attitudebased approaches to leadership are to be successfully utilized. Some of the applications suggested can be easily incorporated into the typical design of leadership research, whereas others would require the use of methodological approaches that are less typical in this context. Each section of this review has associated methodological implications that will be discussed separately below.

\subsection{Attitude content}

As Tables 1 and 2 demonstrate, current measures of different leadership perceptions are based to varying degrees on affect, cognition and behavior. These scales were not designed to measure certain types of attitudes and it is therefore unsurprising that many of the scales represent a mixture of different content. As the content of one's attitude can be a powerful determinant of future behavior it would be useful to have clear distinctions between affective, cognitive and behavioral components of leadership attitudes. Thus future research should aim to develop scales that tap into the different components that make up a given leadership attitude. Specifically it would be useful to measure affective, cognitive and behavioral components of each leadership attitude. For example, when measuring LMX knowing a 
follower's affective, cognitive and behavioral attitude could potentially increase the predictive validity of the attitude. Such information would allow researchers to determine which attitudinal component is most predictive, for who, and when. This approach would also contribute to research investigating the consistency between these different bases of the attitude and how this impacts on subsequent behavior. As discussed previously, to some extent this rationale has been applied to a limited extent within LMX research with the development of the LMX-MDM measure that explicitly measures an affective dimension (Liden \& Maslyn, 1998). However, to date, little attention has been paid to potential differences between these variables and many studies aggregate the scale to an overall score. Therefore, it is unclear whether the affective dimension of the LMX-MDM has differential effects to the cognitive and behavioral dimensions (such as work performance, Martin, Guillaume, Thomas, Lee, \& Epitropaki, 2015).

\subsection{Attitude structure}

Measures of leadership perception focus on the valence and extremity of leadership attitudes. This is because researchers are interested in the extent that followers view their leader as 'transformational', 'servant' or 'authentic'. Such measures fail to account for other dimensions of an attitude, related to attitude strength, that have been show to influence the impact of an attitude. As can be seen in Table 3, some of the features related to attitude strength reflect inherently subjective perceptions of the attitude-holder. Attitude strength dimensions that rely on subjective judgements are well suited to measurement in surveys. Krosnick and Abelson (1991) suggest that five attitude strength dimensions are suitable measures for surveys: extremity, intensity, certainty, importance and knowledge.

As well as utilizing the survey design, attitude strength research has often used experimental methods to test hypotheses related to attitude strength (e.g., Maio et al., 1996; Martin \& Hewstone, 2008). Indeed, attitude research more generally often uses such designs to develop and test theoretical propositions. Experimental research in the domain of leadership is far from the norm, however, this type of design is increasing in popularity (e.g., Hoyt, \& 
Blascovich, 2010; Thiel, Connelly, \& Griffith, 2012). Integrating leadership perception into an attitudes framework can serve to encourage researchers to utilize a variety of research designs including experimental approaches.

Other attitude strength dimensions may be harder to measure subjectively as they reflect the content and structure of representations stored in long-term memory. Attitude accessibility signifies the nature of the relation between an object's representation and its evaluation stored in memory, which controls the speed and ease with which the attitude comes to mind upon encountering the object. As discussed previously, Leavitt et al. (2011) measured implicit leadership attitudes utilizing the most widespread tool for capturing implicit attitudes; the Implicit Association Test (IAT), developed by Greenwald, McGhee and Schwartz (1998). The IAT focuses on response latencies as an indicator for the relative associative strength between the two pairs of concepts (Hofmann, Gawronski, Gschwendner, Le, \& Schmitt, 2005). Leavitt et al. (2011) used this method to measure the strength of association between the participant's leader and positive valence. This approach represents a very general implicit leader attitude, however, and it would be interesting to see more research that examines this particular aspect of leadership such as the quality of the relationship. In a related literature, implicit measures have been adapted for the study of close relationships (e.g., Banse \& Kowalick, 2007; Zayas \& Shoda, 2005). Such research designs could be easily adapted to research in attitudes on leadership and leader-follower relationships.

\subsection{Attitude function}

Attitude function can represent a methodological challenge for the study of leadership as one of the most common measures, developed by Shavitt (1990), involves an open-ended, thought listing approach, where participants are asked to list their thoughts associated with an attitude object. These thoughts are then coded to assess the functions they reflected (see Shavitt, 1990). Thoughts related to the utilitarian category, for example, include references to rewards or punishments associated with the object. Social identity thoughts include references 
to others' attitudes toward the leader, what the attitude symbolizes, and what the attitude communicates to others.

Scholars have also developed an inventory to measure attitude function; the Attitude Function Inventory (AFI, Herek, 1987). The AFI provides a direct measure of the different functions in relation to an attitude object and includes items for various categories of attitude function (Experiential-Schematic, Defensive, Value-Expressive and Social-Expressive). This inventory represents a more convenient way for leadership scholar to assess the function of leadership attitudes as this scale can be included in survey based design.

\subsection{Practical implications}

The integration of attitude theory to the leadership domain also highlights important implications for leader training and development. To date, the predominant approach to leadership development programmes has been to develop leader's skills and metacompetencies based on the assumption that this will enhance leadership effectiveness (Day, 2001). Yet, the implications of our review suggest a note of caution is merited. We argue that the loci and mechanisms underlying effective leadership (and thus leadership development) reside in both followers and leaders. This is because any improvements in leadership style must have a corresponding impact upon the underlying structure and content of followers' attitudes and evaluations of the leader's style in order for leader development to be effective and shape followers' behavior. In other words, leadership development is as much about follower attitude change as it is leader behavioral change.

To complicate matters further, our review suggests that once formed, followers' attitudes tend to relatively stable in that they persist over time and resist change, particularly if they are strong attitudes. Leaders need to be aware that followers are likely to detect and interpret behavioral information in a biased manner that helps maintain their current attitude (Maio \& Thomas, 2007). On a more optimistic note, however, our review suggests some mechanisms that may aid follower attitude change. For example, attitude-discrepant behavior 
displayed by leaders needs to be made highly salient and accessible to followers and formally recognized by the performance appraisal systems. In addition, attempts to influence follower's attitudes are likely to be more successful to the extent that they match the underlying content and motivational basis (i.e., function) of the attitude. It is important to note that these attempts to influence are likely to be more effective to the extent that they target the social expressive attitudes of the wider work group, and thus are consistent with the social identity of the work group (Hogg et al., 2012). Taken together, our review implies that a better understanding of how to manage and change followers' attitudes, especially how to strengthen favorable attitudes and weaken unfavorable attitudes, should be an important foci for leadership development programs.

\subsection{Conclusion}

We started this review with the claim that leadership perceptions are synonymous with attitudes and that this perspective can provide an enhanced understanding of the leadership process and therefore advance theory in this area. Based on this, we used an attitude framework to understand leadership perceptions in a number of ways. First, our content analyses showed that current leadership measures vary considerably with respect to measuring the three components of attitudes (affect, cognition and behavior). We propose that leadership perceptions should include all three attitudinal components to adequately assess the concept. Second, that the different components of attitudes might have a differential impact on workrelated outcomes. We propose that because current leadership measures vary with respect to their measurement of the attitudinal components, this might explain differences in findings between these measures. Third, that the properties of an attitude (content, structure and function) can provide new insights into the leadership process. We propose that the examination of these properties encourages a move away from viewing leadership perceptions as a leader-centric property to one that considers both the leader's behavior and the follower's subjective interpretation of that behavior. Fourth, there are many benefits from the application 
of the attitudes framework in terms of potential methodological advances. We propose that these methodological developments encourage the utilization of a more multi-method approach to measuring leadership perceptions and a wider use of research designs. Fifth, the review emphasized that there are many practical benefits from viewing leadership perceptions as an attitude. We propose that this knowledge encourages a move away from focusing on developing leaders' leadership skills and meta-competencies to also include an understanding of how followers form attitudes about their behaviors and how these perceptions can be changed. In conclusion, we propose that there are many potential benefits from applying an attitudes framework to understanding leadership perceptions and we hope our review has demonstrated some of these and that this will help to encourage further research in this area. 


\section{References}

Aarts, H., Verplanken, B., \& Knippenberg, A. (1998). Predicting behavior from actions in the past: Repeated decision making or a matter of habit? Journal of Applied Social Psychology, 28, 1355-1374.

Abelson, R. P. (1995). Attitude extremity. In R. E. Petty \& J. A. Krosnick (Eds.). Attitude strength: Antecedents and consequences (pp. 25-41). Mahwah, NJ: Erlbaum.

Ajzen, I. (1988). Attitudes, personality and behavior. Milton Keynes, UK: Open University Press.

Ajzen, I., \& Fishbein, M. (1980). Understanding attitudes and predicting social behavior. Englewood Cliffs, NJ: Prentice Hall.

Ajzen, I., \& Fishbein, M. (2000). Attitudes and the attitude-behavior relation: Reasoned and automatic processes. European Review of Social Psychology, 11, 1-33.

Allen, N. J., \& Meyer, J. P. (1990). The measurement and antecedents of affective, continuance and normative commitment to the organization. Journal of Occupational Psychology, 63, $1-18$.

Allport GW. 1935. Attitudes. In C Murchison (Ed.), Handbook of social psychology (pp. 798844). Worchester, MA: Clark University Press.

Ansari, M. A., Lee, B. B., \& Aafaqi, R. (2007). LMX and work outcomes: The mediating role of delegation in the Malaysian business context. Academy of Management Proceedings, 1, 1-6.

Armitage, C. J., \& Conner, M. (2000). Attitudinal ambivalence: A test of three key hypotheses. Personality and Social Psychology Bulletin, 26, 1421-1432.

Ashkanasy, N. M., \& O'connor, C. (1997). Value congruence in leader-member exchange. The Journal of Social Psychology, 137, 647-662. 
Avolio, B. J., Bass, B. M., \& Jung, D. I. (1999). Re-examining the components of transformational and transactional leadership using the Multifactor Leadership Questionnaire. Journal of Occupational and Organizational Psychology, 72, 441-462.

Baccus, J. R., Baldwin, M. W., \& Packer, D. J. (2004). Increasing implicit self-esteem through classical conditioning. Psychological Science, 15, 498-502.

Balzer, W.K., Kihm, J.A., Smith, P.C., Irwin, J.L., Bachiochi, P.D., Robie, C., Sinar, E.F., \& Parra, L.F. (1997). Users'manual for the job descriptive index (JDI; 1997 Revision) and the job in general (JIG) scales. Bowling Green, $\mathrm{OH}$ : Bowling Green State University.

Banse, R., \& Kowalick, C. (2007). Implicit attitudes towards romantic partners predict wellbeing in stressful life conditions: Evidence from the antenatal maternity ward. International Journal of Psychology, 42, 149-157.

Bargh, J. A., Chaiken, S., Govender, R., \& Pratto, F. (1992). The generality of the automatic attitude activation effect. Journal of Personality and Social Psychology, 62, 893-912.

Bargh, J. A., \& Chartrand, T. L. (1999). The unbearable automaticity of being. American Psychologist, 54, 462 - 479.

Barling, J., Weber, T., \& Kelloway, E. K. (1996). Effects of transformational leadership training on attitudinal and financial outcomes: A field experiment. Journal of Applied Psychology, 81, 827-832.

Bass, B. M. (1985). Leadership performance beyond expectations. New York: Academic Press.

Bass, B.M. (1998). Transformational Leadership: Industrial, Military, and Educational Impact. Lawrence Erlbaum Associates, Mahwah, NJ.

Bass, B. M. \& Avolio, B. J. (1990). Transformational leadership development: Manual for the Multifactor Leadership Questionnaire. Palo Alto, CA: Consulting Psychologist Press.

Bass, B. M., \& Avolio, B. J. (1995). The Muttifactor Leadership Questionnaire. Palo Alto, CA: Mind Garden. 
Bassili, J. N. (1996). Meta-judgmental versus operative indexes of psychological attributes:

The case of measures of attitude strength. Journal of Personality and Social Psychology, $71,637-653$.

Bauer, T. N., \& Green, S. G. (1996). Development of leader-member exchange: A longitudinal test. Academy of Management Journal, 39, 1538 - 1567.

Bernerth, J. B., Armenakis, A. A., Feild, H. S., Giles, W. F., \& Walker, H. J. (2007). Is personality associated with perceptions of LMX? An empirical study. Leadership \& Organization Development Journal, 28, 613-631.

Boer, D., \& Fischer, R. (2013). How and when do personal values guide our attitudes and sociality? Explaining cross-cultural variability in attitude-value linkages. Psychological Bulletin, 139, 1113-1147.

Boninger, D. S., Krosnick, J. A., \& Berent, M. K. (1995). Origins of Attitude Importance: Selfinterest, Social Identification, and Value Relevance. Journal of Personality and Social Psychology, 68, 61-80.

Bommer, W. H., Rich, G. A., \& Rubin, R. S. (2005). Changing attitudes about change: Longitudinal effects of transformational leader behavior on employee cynicism about organizational change. Journal of Organizational Behavior, 26, 733-753.

Bono, J. E., \& Judge, T. A. (2003). Self-concordance at work: Toward understanding the motivational effects of transformational leaders. Academy of Management Journal, 46, $554-571$.

Bradburn, N. M., \& Caplovitz, D. (1965). Reports on happiness. Aldine Publishing Company. Brannon, L. A., Tagler, M. J., \& Eagly, A. H. (2007). The moderating role of attitude strength in selective exposure to information. Journal of Experimental Social Psychology, 43, 611-617.

Brayfield, A. H., \& Rothe, H. F. (1951). An index of job satisfaction. Journal of Applied Psychology, 35,307-311. 
Breckler, S. J., \& Wiggins, E. C. (1989). Affect versus evaluation in the structure of attitudes. Journal of Experimental Social Psychology, 25, 253-271.

Breckler, S. J., \& Wiggins, E. C. (1991). Cognitive responses in persuasion: Affective and evaluative determinants. Journal of Experimental Social Psychology, 27, 180-200.

Brömer, P. (1998). Ambivalent attitudes and information processing. Swiss Journal of Psychology, 57, 225-234.

Brown, M. E., Treviño, L. K., \& Harrison, D. A. (2005). Ethical leadership: A social learning perspective for construct development and testing. Organizational Behavior and Human Decision Processes, 97, 117-134.

Buchan, H. F. (2005). Ethical decision making in the public accounting profession: An extension of Ajzen's theory of planned behavior. Journal of Business Ethics, 61, 165181.

Cacioppo, J. T., Gardner, W. L., \& Berntson, G. G. (1997). Beyond bipolar conceptualizations and measures: The case of attitudes and evaluative space. Personality and Social Psychology Review, 1, 3-25.

Cacioppo, J. T., Petty, R. E., Feinstein, J. A., \& Jarvis, W. B. G. (1996). Dispositional differences in cognitive motivation: The life and times of individuals varying in need for cognition. Psychological Bulletin, 119, 197-253.

Cantril, H. (1946). The intensity of an attitude. The Journal of Abnormal and Social Psychology, 41, 129-135.

Carver, C. S., \& Scheier, M. F. (1998). On the self-regulation of behavior. New York: Cambridge University Press.

Chaiken, S., Pomerantz, E.M., \& Giner-Sorolla, R. (1995). Structural consistency and attitude strength. In R.E. Petty \& J.A. Krosnick (Eds.), Attitude strength: Antecedents and consequences (pp. 387-412). Mahwah, NJ: Erlbaum. 
Conner, M., Povey, R., Sparks, P., James, R., \& Shepherd, R. (2003). Moderating role of attitudinal ambivalence within the theory of planned behavior. British Journal of Social Psychology, 42, 75-94.

Cooke, R., \& Sheeran, P. (2004). Moderation of cognition-intention and cognition-behavior relations: A meta-analysis of properties of variables from the theory of planned behavior. British Journal of Social Psychology, 43, 159-186.

Crites, S. L., Fabrigar, L. R., \& Petty, R. E. (1994). Measuring the affective and cognitive properties of attitudes: Conceptual and methodological issues. Personality and Social Psychology Bulletin, 20, 619-634.

Dansereau, F., Cashman, J., \& Graen, G. (1973). Instrumentality theory and equity theory as complementary approaches in predicting the relationship of leadership and turnover among managers. Organizational Behavior and Human Performance, 10, 184-200.

Day, D. V. (2001). Leadership development: A review in context. The Leadership Quarterly, 11, 581-613.

De Hoogh, A. H., Den Hartog, D. N., \& Koopman, P. L. (2005). Linking the Big Five-Factors of personality to charismatic and transactional leadership; perceived dynamic work environment as a moderator. Journal of Organizational Behavior, 26, 839-865.

De Houwer, J., \& Moors, A. (2007). How to define and examine the implicitness of implicit measures. In B. Wittenbrink \& N. Schwarz (Eds.), Implicit measures of attitudes: Procedures and controversies (pp. 179-194). New York: Guilford Press.

De Wit, R., Victoir, A., \& Van den Bergh, O. (1997). 'My mind's made up by the way that I feel': affect, cognition and intention in the structure of attitudes toward condom use. Health Education Research, 12, 15-24.

Dienesch, R.M. (1985). A three dimensional model of leader-member exchange: An empirical test. Paper presented at the Academy of Management annual meeting, San Diego, CA. 
Dvir, T., Eden, D., Avolio, B. J., \& Shamir, B. (2002). Impact of transformational leadership on follower development and performance: A field experiment. Academy of Management Journal, 45, 735-744.

Eagly, A. H., \& Chaiken, S. (1993). The psychology of attitudes. Fort Worth, TX: Harcourt Brace Jovanovich.

Eagly, A. H., Mladinic, A., \& Otto, S. (1994). Cognitive and affective bases of attitudes toward social groups and social policies. Journal of Experimental Social Psychology, 30, 113137.

Eaton, A. A., Majka, E. A., \& Visser, P. S. (2008). Emerging perspectives on the structure and function of attitude strength. European Review of Social Psychology, 19, 165-201.

Edwards, K. (1990). The interplay of affect and cognition in attitude formation and change. Journal of Personality and Social Psychology, 59, 202-216.

Edwards, K., \& Von Hippel, W. (1995). Hearts and minds: The priority of affective versus cognitive factors in person perception. Personality and Social Psychology Bulletin, 21, 996-1011.

Ehrhart, M. G., \& Klein, K. J. (2001). Predicting followers' preferences for charismatic leadership: The influence of follower values and personality. The Leadership Quarterly, 12, 153-179.

Ellemers, N., De Gilder, D., \& Haslam, S. A. (2004). Motivating individuals and groups at work: A social identity perspective on leadership and group performance. Academy of Management Review, 29, 459-478.

Elliott, M. A., Armitage, C. J., \& Baughan, C. J. (2003). Drivers' compliance with speed limits: an application of the theory of planned behavior. Journal of Applied Psychology, 88, 964-972.

Engle, E. M., \& Lord, R. G. (1997). Implicit theories, self-schemas, and leader-member exchange. Academy of Management Journal, 40, 988-1010. 
Epitropaki, O., \& Martin, R. (2004). Implicit leadership theories in applied settings: Factor structure, generalizability, and stability over time. Journal of Applied Psychology, 89, 293-310.

Epitropaki, O., \& Martin, R. (2005). From ideal to real: A longitudinal study of the role of implicit leadership theories on leader-member exchanges and employee outcomes. Journal of Applied Psychology, 90, 659-676.

Epitropaki, O., \& Martin, R. (2013). Transformational-transactional leadership and upward influence: The role of Relative Leader-Member Exchanges (RLMX) and Perceived Organizational Support (POS). The Leadership Quarterly, 24, 299-315.

Esses, V. M., Haddock, G., \& Zanna, M. P. (1993). Values, stereotypes, and emotions as determinants of intergroup attitudes. In D. M. Mackie \& D. L. Hamilton (Eds.), Affect, cognition, and stereotyping: Interactive processes in group perception (pp. 137-166). San Diego, CA: Academic Press.

Fazio, R. H. (1986). How do attitudes guide behavior? In R. M. Sorrentino \& E. T. Higgins (Eds.), Handbook of motivation and cognition: Foundations of social behavior (pp. 129150). New York: Guilford.

Fazio, R. H. (1990). Multiple processes by which attitudes guide behavior: The MODE model as an integrative framework. Advances in Experimental Social Psychology, 23, 75-109.

Fazio, R. H. (1995). Attitudes as object-evaluation associations: Determinants, consequences, and correlates of attitude accessibility. In R.E. Petty and J.A. Krosnick (Eds.), Attitude strength: Antecedents and consequences (pp. 247-282). Hillsdale, NJ: Erlbaum.

Fazio, R. H., \& Zanna, M. P. (1978). Attitudinal qualities relating to the strength of the attitude-behavior relationship. Journal of Experimental Social Psychology, 14, 398-408.

Festinger, L. (1957). A theory of cognitive dissonance. Stanford, CA: Stanford University Press. 
Fishbein, M. (1967). Attitude and the prediction of behavior. In M. Fishbein (Ed.), Readings in attitude theory and measurement. New York: Wiley.

Fishbein, M., \& Ajzen, I. (1975). Belief, attitude, intention, and behavior: An introduction to theory and research. Reading, MA: Addison-Wesley.

Fisher, C. D. (1980). On the dubious wisdom of expecting job satisfaction to correlate with performance. Academy of Management Review, 5, 607-612.

Fisher, C. D. (2000). Mood and emotions while working: Missing pieces of job satisfaction? Journal of Organizational Behavior, 21,185-202.

Fisher, M., \& Keil, F. C. (2014). The illusion of argument justification. Journal of Experimental Psychology: General, 143, 425-433.

George, J. M., \& Jones, G. R. (2000). The role of time in theory and theory building. Journal of Management, 26, 657-684.

Glaser, J., \& Salovey, P. (1998). Affect in electoral politics. Personality and Social Psychology Review, 2, 156-172.

Glasman, L. R., \& Albarracin, D. (2006). Forming attitudes that predict future behavior: A meta-analysis of the attitude-behavior relation. Psychological Bulletin, 132, 778-822.

Gong, Y., Huang, J. C., \& Farh, J. L. (2009). Employee learning orientation, transformational leadership, and employee creativity: The mediating role of employee creative selfefficacy. Academy of Management Journal, 52, 765-778.

Graen, G. B., \& Uhl-Bien, M. (1995). Relationship-based approach to leadership: Development of leader-member exchange (LMX) theory of leadership over 25 years: Applying a multi-level multi-domain perspective. The Leadership Quarterly, 6, 219-247. Greenleaf, R.K. (1977). Servant leadership. New York: Paulist Press.

Greenwald, A.G., \& Banaji, M.R. (1995). Implicit social cognition: Attitudes, self-esteem, and stereotypes. Psychological Review, 102, 4-27. 
Greenwald, A.G., McGhee, D.E., \& Schwartz, J.L. (1998). Measuring individual differences in implicit cognition: The Implicit Association Test. Journal of Personality and Social Psychology, 74, 1464-1480.

Greenwald, A.G., Smith, C.T., Sriram, N., Bar-Anan, Y., \& Nosek, B.A. (2009). Implicit race attitudes predicted vote in the 2008 US presidential election. Analyses of Social Issues and Public Policy, 9, 241-253.

Greguras, G. J., \& Ford, J. M. (2006). An examination of the multidimensionality of supervisor and subordinate perceptions of leader-member exchange. Journal of Occupational and Organizational Psychology, 79, 433-465.

Haddock, G., \& Maio, G. R. (Eds.). (2004). Contemporary perspectives on the psychology of attitudes. Philadelphia: Psychology Press.

Haddock, G., Maio, G. R., Arnold, K., \& Huskinson, T. (2008). Should persuasion be affective or cognitive? The moderating effects of need for affect and need for ognition. Personality and Social Psychology Bulletin, 34, 769-778.

Haddock, G., Zanna, M. P., \& Esses, V. M. (1993). Assessing the structure of prejudicial attitudes: the case of attitudes towards homosexuals. Journal of Personality and Social Psychology, 65, 1105-1118.

Hamilton, D. L., Sherman, S. J., \& Ruvolo, C. M. (1990). Stereotype-based expectancies: Effects on information processing and social behavior. Journal of Social Issues, 46, 3560.

Hansbrough, K., Lord, R.G., \& Schyns, B. (2014). Reconsidering the accuracy of follower leadership ratings. The Leadership Quarterly, 26, 220-237.

Harding, J., Kutner, B., Proshansky, H., \& Chein, I. (1954). Prejudice and ethnic relations. In G. Lindzey (Ed.), Handbook of social psychology (Vol. 2, pp. 1021-1061). Cambridge, MA: Addison-Wesley. 
Harris, K. J., Wheeler, A. R., \& Kacmar, K. M. (2009). Leader-member exchange and empowerment: Direct and interactive effects on job satisfaction, turnover intentions, and performance. The Leadership Quarterly, 20, 371-382.

Harrison, D. A., Newman, D. A., \& Roth, P. L. (2006). How important are job attitudes? Metaanalytic comparisons of integrative behavioral outcomes and time sequences. Academy of Management Journal, 49, 305-325.

Hart, W., Albarracín, D., Eagly, A. H., Brechan, I., Lindberg, M. J., \& Merrill, L. (2009). Feeling validated versus being correct: A meta-analysis of selective exposure to information. Psychological Bulletin, 135, 555-588.

Henderson, D. J., Wayne, S. J., Shore, L. M., Bommer, W. H., \& Tetrick, L. E. (2008). Leader--member exchange, differentiation, and psychological contract fulfilment: A multilevel examination. Journal of Applied Psychology, 93, 1208-1219.

Herek, G. M. (1987). Can functions be measured? A new perspective on the functional approach to attitudes. Social Psychology Quarterly, 50, 285-303.

Hetland, H., Hetland, J., Schou Andreassen, C., Pallesen, S., \& Notelaers, G. (2011). Leadership and fulfillment of the three basic psychological needs at work. Career Development International, 16, 507-523.

Hinkin, T. R., \& Schriesheim, C. A. (2008). An examination of" nonleadership": from laissezfaire leadership to leader reward omission and punishment omission. The Journal of Applied Psychology, 93, 1234-1248.

Hinkin, T. R., \& Tracey, J. B. (1999). An analysis of variance approach to content validation. Organizational Research Methods, 2, 175-186.

Hochschild, J., (1981). What's Fair? Cambridge, MA: Harvard University Press.

Hofmann, W., Gawronski, B., Gschwendner, T., Le, H., \& Schmitt, M. (2005). A metaanalysis on the correlation between the Implicit Association Test and explicit self-report measures. Personality and Social Psychology Bulletin, 31, 1369-1385. 
Hogan, R., \& Kaiser, R. B. (2005). What we know about leadership. Review of General Psychology, 9, 169-180.

Hogg, M. A. (2001). A social identity theory of leadership. Personality and Social Psychology Review, 5, 184-200.

Hogg, M. A., \& van Knippenberg, D. (2003). Social identity and leadership processes in groups. Advances in Experimental Social Psychology, 35, 1-52.

Hogg, M. A., Van Knippenberg, D., \& Rast, D. E. (2012). Intergroup leadership in organizations: Leading across group and organizational boundaries. Academy of Management Review, 37, 232-255.

Holbrook, A. L., Berent, M. K., Krosnick, J. A., Visser, P. S., \& Boninger, D. S. (2005). Attitude importance and the accumulation of attitude-relevant knowledge in memory. Journal of Personality and Social Psychology, 88, 749-769.

Holland, R. W., Verplanken, B., \& Van Knippenberg, A. (2002). On the nature of attitudebehavior relations: The strong guide, the weak follow. European Journal of Social Psychology, 32, 869-876.

Holton, B., \& Pyszczynski, T. (1989). Biased information search in the interpersonal domain. Personality and Social Psychology Bulletin, 15, 42-51.

Hoyt, C. L., \& Blascovich, J. (2010). The role of leadership self-efficacy and stereotype activation on cardiovascular, behavioral and self-report responses in the leadership domain. The Leadership Quarterly, 21, 89-103.

Hu, J., \& Liden, R.C. (2013). Relative leader-member exchange within team contexts: how and when social comparison impacts individual effectiveness. Personnel Psychology, 66, $127-172$.

Hulin, C. L. (1991). Adaptation, persistence, and commitment in organizations. In M. D. Dunnette \& L. M. Hough (Eds.), Handbook of industrial and organizational psychology, (Vol. 2, pp. 445-505). Palo Alto, CA: Consulting Psychologists Press. 
Huskinson, T. L., \& Haddock, G. (2004). Individual differences in attitude structure: Variance in the chronic reliance on affective and cognitive information. Journal of Experimental Social Psychology, 40, 82-90.

Jaramillo, F., Grisaffe, D. B., Chonko, L. B., \& Roberts, J. A. (2009). Examining the impact of servant leadership on salesperson's turnover intention. Journal of Personal Selling \& Sales Management, 29, 351-365.

Javidan, M., House, R. J., Dorfman, P. W., Hanges, P. J., \& De Luque, M. S. (2006). Conceptualizing and measuring cultures and their consequences: a comparative review of GLOBE's and Hofstede's approaches. Journal of International Business Studies, 37, 897914.

Jimmieson, N. L., Peach, M., \& White, K. M. (2008). Utilizing the Theory of Planned Behavior to inform change management: An Investigation of employee Intentions to support organizational change. Journal of Applied Behavioral Science, 44, 237-262.

Johnson, R. E., \& Lord, R. G. (2010). Implicit effects of justice on self-identity. Journal of Applied Psychology, 95, 681 - 695.

Johnson, R. E., \& Saboe, K. N. (2011). Measuring implicit traits in organizational research: Development of an indirect measure of employee implicit self-concept. Organizational Research Methods, 14, 530-547.

Johnson, R. E., Tolentino, A. L., Rodopman, O. B., \& Cho, E. (2010). We (sometimes) know not how we feel: Predicting job performance with an implicit measure of trait affectivity. Personnel Psychology, 63, 197-219.

Jonas, K., Diehl, M., \& Brömer, P. (1997). Effects of attitudinal ambivalence on information processing and attitude-intention consistency. Journal of Experimental Social Psychology, 33, 190-210.

Jonas, E., Schulz-Hardt, S., Frey, D., \& Thelen, N. (2001). Confirmation bias in sequential information search after preliminary decisions: An expansion of dissonance theoretical 
research on selective exposure to information. Journal of Personality and Social Psychology, 80, 557-571.

Judge, T. A., \& Kammeyer-Mueller, J. D. (2012). Job attitudes. Annual Review of Psychology, 63, 341-367.

Judge, T. A., \& Piccolo, R. F. (2004). Transformational and transactional leadership: A metaanalytic test of their relative validity. Journal of Applied Psychology, 89, 755-768.

Jung, D. I., \& Avolio, B. J. (2000). Opening the black box: An experimental investigation of the mediating effects of trust and value congruence on transformational and transactional leadership. Journal of Organizational Behavior, 21, 949-964.

Karpinski, A., Steinman, R. B., \& Hilton, J. L. (2005). Attitude importance as a moderator of the relationship between implicit and explicit attitude measures. Personality and Social Psychology Bulletin, 31, 949-962.

Katz, D. (1960). The functional approach to the study of attitudes. Public Opinion Quarterly, 24, 163-204.

Katz, D., \& Stotland, E. (1959). A preliminary statement to a theory of attitude structure and change. In S. Koch (Ed.), Psychology: A study of a science (Vol. 3, pp. 423-475). New York: McGraw-Hill.

Kay, A. C., Wheeler, S. C., Bargh, J. A., \& Ross, L. (2004). Material priming: The influence of mundane physical objects on situational construal and competitive behavioral choice. Organizational Behavior and Human Decision Processes, 95, 83-96.

Kendall, P. (1954). Conflict and mood: Factors affecting stability of response. Glencoe, IL: The Free Press.

Kenney, R. A., Schwartz-Kenney, B. M., \& Blascovich, J. (1996). Implicit leadership theories: Defining leaders described as worthy of influence. Personality and Social Psychology Bulletin, 22, 1128-1143. 
Khan, S. N., Qureshi, I. M., \& Ahmad, H. I. (2010). Abusive supervision and negative employee outcomes. European Journal of Social Sciences, 15, 490-500.

Kiger, G. (1997). The structure of attitudes toward persons who are deaf: Emotions, values, and stereotypes. Journal of Psychology, 131, 554-560.

Kinicki, A.J., McKee-Ryan, F.M., Schriesheim, C.A., \& Carson, K.P. (2002). Assessing the construct validity of the Job Descriptive Index: A review and meta-analysis. Journal of Applied Psychology, 87, 14-32.

Kirkpatrick, S. A., \& Locke, E. A. (1996). Direct and indirect effects of three core charismatic leadership components on performance and attitudes. Journal of Applied Psychology, 81, $36-51$.

Kovjanic, S., Schuh, S. C., Jonas, K., Quaquebeke, N. V., \& Dick, R. (2012). How do transformational leaders foster positive employee outcomes? A self-determination-based analysis of employees' needs as mediating links. Journal of Organizational Behavior, 33, 1031-1052.

Kraus, S. J. (1995). Attitudes and the prediction of behavior: A meta-analysis of the empirical literature. Personality and Social Psychology Bulletin, 21, 58-75.

Krosnick, J. A., \& Abelson, R. P. (1991). The case for measuring attitude strength in surveys. In J. M. Tanur (Ed.), Questions about questions (pp. 177-203). New York: Russell Sage. Krosnick, J. A., \& Petty, R. E. (1995). Attitude strength: An overview. In R. E. Petty \& J. A. Krosnick (Eds.), Attitude strength: Antecedents and consequences (pp. 1-24). Mahwah, NJ: Lawrence Erlbaum Associates.

Kunda, Z. (1990). The Case for Motivated Reasoning. Psychological Bulletin, 108, 480-498.

Law, K. S., Wang, H., \& Hui, C. (2010). Currencies of exchange and global LMX: How they affect employee task performance and extra-role performance. Asia Pacific Journal of Management, 27, 625-646. 
Leavitt, K., Fong, C. T., \& Greenwald, A. G. (2011). Asking about well-being gets you half an answer: Intra-individual processes of implicit and explicit job attitudes. Journal of Organizational Behavior, 32, 672-687.

LeBel, E. P., \& Gawronski, B. (2009). How to find what's in a name: Scrutinizing the optimality of five scoring algorithms for the name-letter task. European Journal of Personality, 23, 85-106.

LeBreton, J. M., Barksdale, C. D., Robin, J., \& James, L. R. (2007). Measurement issues associated with conditional reasoning tests: indirect measurement and test faking. Journal of Applied Psychology, 92, 1-16.

Lee, A., Martin, R., Thomas, G., \& Guillaume, Y. (Under Review). Leader-Member Exchange (LMX) and sttitude importance: An integration.

Lee, A., Thomas, G., Martin, R., \& Guillaume, Y. (Under Review). Relational ambivalence in leader-follower dyads.

Leippe, M. R., \& Elkin, R. A. (1987). When motives clash: Issue involvement and response involvement as determinants of persuasion. Journal of Personality and Social Psychology, 52, 269 - 278.

Levy, P. E., Cober, R. T., \& Miller, T. (2002). The effect of transformational and transactional leadership perceptions on feedback-seeking intentions. Journal of Applied Social Psychology, 32, 1703-1720.

Lewter, J., \& Lord, R. G. (1992). Affect, self-schemas and transformational leadership. Paper presented at the Academy of Management Conference, Las Vegas, NV.

Liden, R. C., \& Maslyn, J. M. (1998). Multidimensionality of leader-member exchange: An empirical assessment through scale development. Journal of Management, 24, 43-72.

Liden, R. C., Wayne, S. J., \& Stilwell, D. (1993). A longitudinal study on the early development of leader-member exchanges. Journal of Applied Psychology, 78, 662-674. 
Liden, R. C., Wayne, S. J., Zhao, H., \& Henderson, D. (2008). Servant leadership:

Development of a multidimensional measure and multi-level assessment. The Leadership Quarterly, 19, 161-177.

Lo, M. C., Ramayah, T., \& Kueh Swee Hui, J. (2006). An investigation of leader member exchange effects on organizational citizenship behavior in Malaysia. Journal of Business \& Management, 12, 5-23.

Loi, R., \& Ngo, H. Y. 2009. Work outcomes of relational demography in Chinese vertical dyads. International Journal of Human Resource Management, 20, 1704-1719.

Lord, R. G., Foti, R. J., \& Phillips, J. S. (1982). A theory of leadership categorization. In J. G. Hunt, U. Sekaran, \& C. Schriesheim (Eds.), Leadership: Beyond establishment views (pp. 104 -121). Carbondale, IL: Southern Illinois University Press.

Maio, G. R., Bell, D. W., \& Esses, V. M. (1996). Ambivalence and persuasion: The processing of messages about immigrant groups. Journal of Experimental Social Psychology, 32, 513-536.

Maio, G. R., \& Esses, V. M. (2001). The need for affect: Individual differences in the motivation to approach or avoid emotions. Journal of Personality, 69, 583-614.

Maio, G. R., \& Olson, J. M. (1995). Relations between values, attitudes, and behavioral intentions: The moderating role of attitude function. Journal of Experimental Social Psychology, 31, 266-285.

Maio, G. R., \& Thomas, G. (2007). The epistemic-teleologic model of deliberate selfpersuasion. Personality and Social Psychology Review, 11, 46-67.

Major, B., Testa, M., \& Bylsma, W. H. (1991). Responses to upward and downward social comparisons: The impact of esteem-relevance and perceived control. In J. Suls \& T. A. Wills (Eds.), Social comparison: Contemporary theory and research (pp. 237-260). Hillsdale, NJ: Erlbaum. 
Martin, R., Epitropaki, O., Thomas, G., \& Topakas, A. 2010. A critical review of leadermember relationship (LMX) research: Future prospects and directions. International Review of Industrial and Organizational Psychology, 25, 61-91.

Martin, R., Guillaume, Y. R. F., Thomas, G., Lee, A., \& Epitropaki, O. (2015). Leader-member Exchange (LMX) and performance: A Meta-analytic review. Personnel Psychology. Advance online publication.

Martin, R., \& Hewstone, M. (2008). Majority versus minority influence, message processing and attitude change: The Source-Context-Elaboration model. Advances in Experimental Social Psychology, 40, 237-326.

Mattson, R. E., Paldino, D., \& Johnson, M. D. (2007). The increased construct validity and clinical utility of assessing relationship quality using separate positive and negative dimensions. Psychological Assessment, 19, 146-151.

McEachan, R. R. C., Conner, M., Taylor, N. J., \& Lawton, R. J. (2011). Prospective prediction of health-related behaviors with the theory of planned behavior: A meta-analysis. Health Psychology Review, 5, 97-144.

Millar, M. G., \& Millar, K. U. (1998). The effects of prior experience and thought on the attitude-behavior relation. Social Behavior \& Personality, 26, 105-114.

Millar, M. G., \& Tesser, A. (1992). The role of beliefs and feelings in guiding behavior: The mismatch model. In L. Martin \& A. Tesser (Eds.), Construction of social judgment (pp. 277-300). Hillsdale, NJ: Erlbaum.

Nahrgang, J. D., Morgeson, F. P., \& Ilies, R. (2009). The development of leader-member exchanges: Exploring how personality and performance influence leader and member relationships over time. Organizational Behavior and Human Decision Processes, 108, 256-266.

Neider, L. L., \& Schriesheim, C. A. (2011). The authentic leadership inventory (ALI): Development and empirical tests. The Leadership Quarterly, 22, 1146-1164. 
Nordgren, L. F., van Harreveld, F., \& van der Pligt, J. (2006). Ambivalence, discomfort, and motivated information processing. Journal of Experimental Social Psychology, 42, 252258.

Olson, J. M., \& Zanna, M. P. (1993). Attitudes and attitude change. Annual Review of Psychology, 44,117-154.

Peterson, D. K. (2003). The relationship between ethical pressure, relativistic moral beliefs and organizational commitment. Journal of Managerial Psychology, 18, 557-572.

Petty, R. E., \& Cacioppo, J. T. (1986). The elaboration likelihood model of persuasion (pp. 124). Springer New York.

Petty, R. E., Haugtvedt, C. P., \& Smith, S. M. (1995). Elaboration as a determinant of attitude strength: Creating attitudes that are persistent, resistant, and predictive of behavior. In R. E. Petty \& J. A. Krosnick (Eds.), Attitude strength: Antecedents and consequences. (pp. 93-130) Mahwah, NJ: Lawrence Erlbaum Associates.

Petty, R. E., Wheeler, S. C., \& Bizer, G. B. (2000). Attitude functions and persuasion: An elaboration likelihood approach to matched versus mismatched messages. In G. R. Maio \& J. M. Olson (Eds.), Why we evaluate: Functions of attitudes (pp. 133-162). Mahwah, New Jersey: Lawrence Erlbaum.

Pillai, R., \& Williams, E. A. (2004). Transformational leadership, self-efficacy, group cohesiveness, commitment, and performance. Journal of Organizational Change Management, 17, 144-159.

Phillips, R. L., Duran, C. A., \& Howell, R. D. (1993, November). An examination of the multidimensionality hypothesis of leader-member exchange, using both factor analytic and structural modeling techniques. In Proceedings of the Southern Management Association (pp. 161-163).

Podsakoff, P. M., Bommer, W. H., Podsakoff, N. P., \& MacKenzie, S. B. (2006). Relationships between leader reward and punishment behavior and subordinate attitudes, perceptions, 
and behaviors: A meta-analytic review of existing and new research. Organizational Behavior and Human Decision Processes, 99, 113-142.

Podsakoff, P. M., MacKenzie, S. B., Moorman, R. H., \& Fetter, R. (1990). Transformational leader behaviors and their effects on followers trust in leader, satisfaction, and organizational citizenship behaviors. The Leadership Quarterly, 1, 107-142.

Priester, J. R., \& Petty, R. E. (1996). The gradual threshold model of ambivalence: Relating the positive and negative bases of attitudes to subjective ambivalence. Journal of Personality and Social Psychology, 71, 431-449.

Regan, D. T., \& Fazio, R. (1977). On the consistency between attitudes and behavior: Look to the method of attitude formation. Journal of Experimental Social Psychology, 13, 28-45.

Reynolds, S. J., Leavitt, K., \& DeCelles, K. A. (2010). Automatic ethics: the effects of implicit assumptions and contextual cues on moral behavior. Journal of Applied Psychology, 95, 752-760.

Rosenberg, M. J. A. (1960). A structural theory of attitude dynamics. Public Opinion Quarterly, 24, 319-341.

Schleicher, D. J., Smith, T. A., Casper, W. J., Watt, J. D., \& Greguras, G. J. (2015). It's all in the attitude: The role of job attitude strength in job attitude-outcome relationships. Journal of Applied Psychology. Advance Online Publication.

Schleicher, D. J., Watt, J. D., \& Greguras, G. J. 2004. Reexamining the job satisfactionperformance relationship: The complexity of attitudes. Journal of Applied Psychology, 89, 165-177.

Schriesheim, C., \& Kerr, S. (1974). Psychometric properties of the Ohio State leadership scales. Psychological bulletin, 81, 756-765.

Schriesheim, C. A., Kinicki, A. J., \& Schriesheim, J. F. (1979). The effect of leniency on leader behavior descriptions. Organizational Behavior and Human Performance, 23, 129. 
Schriesheim, C. A. \& Liu, Y. (2013). Attitudes towards the Leader-Member Exchange relationship: A reconceptualization and Operationalization of LMX. Paper Presented at Southern Management Association Annual Meeting, November.

Schriesheim, C. A., Neider, L. L., Scandura, T. A., \& Tepper, B. J. (1992). Development and preliminary validation of a new scale (LMX-6) to measure leader-member exchange in organizations. Educational and Psychological Measurement, 52, 135-147.

Schuman, H., \& Presser, S., (1981). Questions and answers in attitude surveys. Academic Press, Orlando.

Schwarz, N. (2000). Agenda 2000: social judgment and attitudes: warmer, more social, and less conscious. European Journal of Social Psychology, 30, 149-176.

Schwarz, N., \& Bohner, G. (2001). The construction of attitudes. In A. Tesser, \& N. Schwarz (Eds.), Intraindividual processes (Blackwell Handbook of Social Psychology, Vol. 1). Oxford: Blackwell.

Settoon, R. P., Bennett, N., \& Liden, R. C. (1996). Social exchange in organizations: Perceived organizational support, leader-member exchange, and employee reciprocity. Journal of Applied Psychology, 81, 219-227.

Shantz, A., \& Latham, G. P. (2009). An exploratory field experiment of the effect of subconscious and conscious goals on employee performance. Organizational Behavior and Human Decision Processes, 109, 9-17.

Shavitt, S. (1990). The role of attitude objects in attitude functions. Journal of Experimental Social Psychology, 26, 124-148.

Sherif, M., \& Hovland, C. I. (1961). Social judgment: Assimilation and contrast effects in communication. New Haven: Yale University Press.

Sherif, C. W., Sherif, M., \& Nebergall, R. E. (1965). Attitude and attitude change: The social judgment involvement approach. Philadelphia: W. B. Saunders. 
Shondrick, S. J., \& Lord, R. G. (2010). Implicit leadership and followership theories: Dynamic structures for leadership perceptions, memory, leader-follower processes. International Review of Industrial and Organizational Psychology, 25, 1-33.

Simons, J., \& Carey, K. B. (1998). A structural analysis of attitudes toward alcohol and marijuana use. Personality and Social Psychology Bulletin, 24, 727-735.

Sin, H. P., Nahrgang, J. D., \& Morgeson, F. P. (2009). Understanding why they don't see eye to eye: an examination of leader-member exchange (LMX) agreement. Journal of Applied Psychology, 94, 1048-1057.

Smith, M. B., Bruner, J. S., \& White, R. W. (1956). Opinions and personality. New York, NY: John Wiley \& Sons.

Stouffer, S.A., Guttman, L., Suchman, E.A., Lazarsfeld, P.F., Star, S.A., \& Clausen, J.A. (1950). Measurement and prediction. Princeton, NJ: Princeton University Press.

Suh, E. M. (2002). Culture, identity consistency, and subjective well-being. Journal of Personality and Social Psychology, 83, 1378-1391.

Swann, W. B., Jr., Pelham, B. W., \& Chidester, T. R. (1988). Change through paradox: Using self-verification to alter beliefs. Journal of Personality and Social Psychology, 54, $268-273$.

Swanson, J. E., Swanson, E., \& Greenwald, A. G. (2001). Using the Implicit Association Test to investigate attitude-behavior consistency for stigmatised behavior. Cognition \& Emotion, 15, 207-230.

Tepper, B. J. (2000). Consequences of abusive supervision. Academy of Management Journal, $43,178-190$.

Thiel, C. E., Connelly, S., \& Griffith, J. A. (2012). Leadership and emotion management for complex tasks: Different emotions, different strategies. The Leadership Quarterly, 23, $517-533$ 
Thomas, G., Martin, R., \& Riggio, R. E. (2013). Leading groups: Leadership as a group process. Group Processes \& Intergroup Relations, 16, 3-16.

Thompson, M. M., Zanna, M. P., \& Griffin, D. W. (1995). Let's not be indifferent about (attitudinal) ambivalence. In R. E. Petty \& J. A. Krosnick (Eds.), Attitude strength: Antecedents and consequences (pp. 361-386). Mahwah, NJ: Erlbaum.

Tormala, Z. L., \& Petty, R. E. (2002). What doesn't kill me makes me stronger: The effects of resisting persuasion on attitude certainty. Journal of Personality and Social Psychology, 83, 1298-1313.

Trafimow, D., \& Sheeran, P. (1998). Some tests of the distinction between cognitive and affective beliefs. Journal of Experimental Social Psychology, 34, 378-397.

Triandis, H. C. (1977). Interpersonal behavior. Monterey, CA: Brooks/Cole Publishing Company.

Uhlmann, E. L., Leavitt, K., Menges, J. I., Koopman, J., Howe, M., \& Johnson, R. E. (2012). Getting explicit about the implicit: A taxonomy of implicit measures and guide for their use in organizational research. Organizational Research Methods, 15, 553-601.

Van Breukelen, W., Van der Vlist, R., \& Steensma, H. (2004). Voluntary employee turnover: Combining variables from the 'traditional' turnover literature with the theory of planned behavior. Journal of Organizational Behavior, 25, 893-914.

van Knippenberg, D., \& Sitkin, S. B. (2013). A critical assessment of charismatictransformational leadership research: Back to the drawing board? Academy of Management Annals, 7, 1-60.

Vidyarthi, P. R., Liden, R. C., Anand, S., Erdogan, B., \& Ghosh, S. 2010. Where do I stand? Examining the effects of leader-member exchange social comparison on employee work behaviors. Journal of Applied Psychology, 95, 849-861.

Visser, P. S., Bizer, G. Y., \& Krosnick, J. A. (2006). Exploring the latent structure of strengthrelated attitude attributes. Advances in Experimental Social Psychology, 38, 1-67. 
Volmer, J., Niessen, C., Spurk, D., Linz, A., \& Abele, A. E. (2011). Reciprocal relationships between leader-member exchange (LMX) and job satisfaction: A Cross-lagged Analysis. Applied Psychology, 60, 522-545.

Walumbwa, F. O., Avolio, B. J., Gardner, W. L., Wernsing, T. S., \& Peterson, S. J. (2008). Authentic leadership: Development and validation of a theory-based measure. Journal of Management, 34, 89-126.

Wang, H., Law, K. S., \& Chen, Z. X. (2008). Leader-member exchange, employee performance, and work outcomes: an empirical study in the Chinese context. International Journal of Human Resource Management, 19, 1809-1824.

Wat, D., \& Shaffer, M. A. (2005). Equity and relationship quality influences on organizational citizenship behaviors: The mediating role of trust in the supervisor and empowerment. Personnel Review, 34, 406-422.

Wayne, S. J., \& Ferris, G. R. (1990). Influence tactics, affect, and exchange quality in supervisor-subordinate interactions: A laboratory experiment and field study. Journal of Applied Psychology, 75, 487-499.

Wegener, D. T., Petty, R. E., Smoak, N. D., \& Fabrigar, L. R. 2004. Multiple routes to resisting attitude change. In E. S. Knowles \& J. A. Linn (Eds.), Resistance and persuasion (pp. 13-38). Mahwah, NJ: Lawrence Erlbaum Associates.

Weiss, D. J., Dawis, R. V., England, G. W., \& Lofquist, L. H. (1967). Manual for the Minnesota Satisfaction Questionnaire. Minnesota studies for vocational rehabilitation (No. XXII). Minneapolis: Industrial Relations Center, University of Minnesota.

Weiss, H. M. (2002). Deconstructing job satisfaction: Separating evaluations, beliefs, and affective experiences. Human Resource Management Review, 12,1-22.

Wicker, A. W. (1969). Attitudes versus actions: The relationship of verbal and overt behavioral responses to attitude objects. Journal of Social issues, 25, 41-78. 
Williams, L. J., \& Anderson, S. E. (1991). Job satisfaction and organizational commitment as predictors of organizational citizenship and in-role behaviors. Journal of Management, 17, 601-617.

Wilson, T. D. (2002). Strangers to ourselves: Discovering the adaptive unconscious. Cambridge, MA: Harvard Univ. Press.

Wilson, T. D., \& Hodges, S. D. (1992). Attitudes as temporary constructions. In L. L. Martin, \& A. Tesser (Eds.), The construction of social judgments (pp. 37-65). Hillsdale, NJ: Erlbaum.

Wilson, T. D., Lindsey, S., \& Schooler, T. Y. (2000). A model of dual attitudes. Psychological review, 107, 101-126.

Wood W, Rhodes N, Biek M. (1995). Working knowledge and attitude strength: an information processing analysis. . In R. E. Petty \& J. A. Krosnick (Eds.), Attitude strength: Antecedents and consequences (pp. 283-313). Mahwah, NJ: Lawrence Erlbaum Associates.

Yukl, G. (2002). Leadership in organizations (5th ed.). Prentice Hall, Upper Saddle River, NJ. Yukl, G. and Seifert, C.F. (2002). Preliminary validation research on the extended version of the influence behaviors questionnaire. Paper presented at the Society for Industrial and Organizational Psychology annual conference, Toronto.

Zaller, J. R. (1992). The nature and origins of mass opinion. Cambridge University Press.

Zanna, M. P., \& Rempel, J. K. (1984). Attitudes: A new look at an old concept. Paper presented at the Conference on the Social Psychology of Knowledge, Tel Aviv, Israel.

Zanna, M. P., \& Rempel, J. K. (1988). Attitudes: A new look at an old concept. In Bartal, D. \& Kruglanski, A. W. (Eds.), The social psychology of knowledge (pp. 315-334). Cambridge, UK: Cambridge University Press. 
Zayas, V., \& Shoda, Y. (2005). Do automatic reactions elicited by thoughts of romantic partner, mother, and self relate to adult romantic attachment? Personality and Social Psychology Bulletin, 31, 1011-1025.

Zhou, X. T., \& Schriesheim, C. A. (2009). Supervisor-subordinate convergence in descriptions of leader-member exchange (LMX) quality: Review and testable propositions. The Leadership Quarterly, 20, 920-932.

Zhou, X. T., \& Schriesheim, C. A. (2010). Quantitative and qualitative examination of propositions concerning supervisor-subordinate convergence in descriptions of leadermember exchange (LMX) quality. The Leadership Quarterly, 21, 826-843.

Ziegler, R., Schlett, C., Casel, K., \& Diehl, M. (2012). The role of job satisfaction, job ambivalence, and emotions at work in predicting organizational citizenship behavior. Journal of Personnel Psychology, 11, 176 - 190.

Zuwerink, J. R., \& Devine, P. G. (1996). Attitude importance and resistance to persuasion: It's not just the thought that counts. Journal of Personality and Social Psychology, 70, 931 944. 
Table 1: Content Analysis of Popular Scales Measuring Leadership Perceptions

\begin{tabular}{|c|c|c|c|c|c|}
\hline Leadership Theory & Measurement scale & Example Items & $\begin{array}{c}\text { Number of } \\
\text { Affective Items }\end{array}$ & $\begin{array}{c}\text { Number of } \\
\text { Cognitive Items }\end{array}$ & $\begin{array}{c}\text { Number of } \\
\text { Behavioral } \\
\text { Items }\end{array}$ \\
\hline LMX & $\begin{array}{l}\text { LMX-7 (Graen \& } \\
\text { Uhl-Bien, 1995) }\end{array}$ & $\begin{array}{l}\text { 1. How well does your leader understand your job } \\
\text { problems and needs? } \\
\text { 2. How well does your leader recognize your potential? }\end{array}$ & 0 & 6 & 1 \\
\hline LMX & $\begin{array}{l}\text { LMX-MDM (Liden } \\
\text { and Maslyn 1998) }\end{array}$ & $\begin{array}{l}\text { I. like my supervisor very much as a person (Affect } \\
\text { Dimension) } \\
\text { 2. I admire my supervisor's professional skills } \\
\text { (Professional Respect Dimension) }\end{array}$ & 6 & 3 & 3 \\
\hline Transformational & $\begin{array}{l}\text { TLI (Podsakoff, } \\
\text { MacKenzie, } \\
\text { Moorman \& Fetter } \\
\text { 1990). }\end{array}$ & $\begin{array}{l}\text { 1. Has a clear understanding of where we are going } \\
\text { 2. Provides a good model to follow }\end{array}$ & 5 & 17 & 0 \\
\hline Transformational & $\begin{array}{l}\text { Subsets of MLQ } \\
\text { (Avolio \& Bass, } \\
\text { 1999). }\end{array}$ & $\begin{array}{l}\text { 1. Talks about his/her most important values and beliefs } \\
\text { 2. Talks optimistically about the future }\end{array}$ & 4 & 16 & 0 \\
\hline Transactional & $\begin{array}{l}\text { Subset of MLQ } \\
\text { (Avolio \& Bass, } \\
\text { 1999). }\end{array}$ & $\begin{array}{l}\text { 1. Makes clear what one can expect to receive when } \\
\text { performance goals are achieved } \\
\text { 2. Keeps track of all mistakes }\end{array}$ & 0 & 9 & 0 \\
\hline Authentic & $\begin{array}{c}\text { Authentic } \\
\text { Leadership } \\
\text { Questionnaire - } \\
\text { Walumbwa, Avolio, } \\
\text { Gardner, Wernsing, }\end{array}$ & $\begin{array}{l}\text { 1. Seeks feedback to improve their interactions with } \\
\text { others } \\
\text { 2. Knows when it is time to re-evaluate their position on } \\
\text { important issues }\end{array}$ & 0 & 16 & 0 \\
\hline
\end{tabular}




\begin{tabular}{|c|c|c|c|c|c|}
\hline & \& Peterson, 2008). & & & & \\
\hline Authentic & $\begin{array}{l}\text { Neider, \& } \\
\text { Schriesheim. } \\
\text { (2011). }\end{array}$ & $\begin{array}{l}\text { 1. My leader openly shares information with others } \\
\text { 2. My leader objectively analyzes relevant data before } \\
\text { making a decision }\end{array}$ & 0 & 16 & 0 \\
\hline Ethical & $\begin{array}{l}\text { Ethical Leadership } \\
\text { Scale - Brown, } \\
\text { Trevino, \& Harrison } \\
\text { (2005) }\end{array}$ & $\begin{array}{l}\text { 1. Can be trusted } \\
\text { 2. Sets an example of how to do things the right way in } \\
\text { terms of ethics }\end{array}$ & 4 & 6 & 0 \\
\hline Servant & $\begin{array}{c}\text { Barbuto, \& } \\
\text { Wheeler(2006) }\end{array}$ & $\begin{array}{l}\text { 1. This person is one I would turn to if I had a personal } \\
\text { trauma } \\
\text { 2. This person sacrifices his/her own interests to meet my } \\
\text { needs }\end{array}$ & 5 & 18 & \\
\hline Servant & $\begin{array}{c}\text { Servant Leadership } \\
\text { Questionnaire } \\
\text { (SLQ) - Liden, } \\
\text { Wayne, Zhao, \& } \\
\text { Henderson (2008) }\end{array}$ & $\begin{array}{l}\text { 1. My manager is always interested in helping people in } \\
\text { our community } \\
\text { 2. I am encouraged by my manager to volunteer in the } \\
\text { community. }\end{array}$ & 3 & 20 & 5 \\
\hline Abusive & $\begin{array}{l}15 \text { items scale - } \\
\text { Tepper (2000) }\end{array}$ & $\begin{array}{l}\text { 1. Breaks promises he/she makes } \\
\text { 2. Is rude to me }\end{array}$ & 15 & 0 & 0 \\
\hline $\begin{array}{l}\text { Satisfaction with } \\
\text { Supervision }\end{array}$ & $\begin{array}{l}\text { Subset of Job } \\
\text { Descriptive Index - } \\
\text { 2009 revision (JDI; } \\
\text { Balzer et al. 1997) }\end{array}$ & $\begin{array}{l}\text { 1. Around when needed } \\
\text { 2. Tells me where I stand }\end{array}$ & 7 & 11 & 0 \\
\hline Effectiveness & $\begin{array}{l}\text { e.g. De Hoogh, Den } \\
\text { Hartog, \& } \\
\text { Koopman }(2005) \text {. }\end{array}$ & $\begin{array}{l}\text { 1. How capable is the person you are evaluating as a } \\
\text { leader } \\
\text { 2. To what extent is the overall functioning of the person } \\
\text { you evaluate satisfactory }\end{array}$ & 0 & 3 & 0 \\
\hline
\end{tabular}


Table 2: ANOVA Results for the Content of Leadership Items

\begin{tabular}{|c|c|c|c|c|c|c|c|}
\hline Items & $M \operatorname{cog}^{1}$ & Maff $^{2}$ & Mbeh $^{3}$ & $1-2(95 \% \mathrm{Cl})$ & $1-3(95 \% \mathrm{Cl})$ & $2-3(95 \% \mathrm{Cl})$ & Conclusion \\
\hline LMX1* & 4.14 & 2.50 & 1.96 & $1.64(.68,2.61)$ & $2.18(1.41,2.95)$ & $.54(-.22,1.29)$ & Cognitive \\
\hline LMX2 & 4.50 & 2.32 & 1.68 & $2.18(1.49,2.86)$ & $2.82(2.30,3.34)$ & $.64(.04,1.24)$ & Cognitive \\
\hline LMX3 & 4.25 & 2.36 & 1.86 & $1.89(1.26,2.53)$ & $2.39(1.69,3.09)$ & $.50(-.14,1.14)$ & Cognitive \\
\hline LMX4 & 3.68 & 2.00 & 2.57 & $1.68(.925,2.43)$ & $1.11(.09,2.12)$ & $-.57(-1.23, .08)$ & Cognitive \\
\hline LMX5 & 3.46 & 2.36 & 2.39 & $1.11(.19,2.02)$ & $1.07(.09,2.04)$ & $-.04(-.76, .68)$ & Cognitive \\
\hline LMX6 & 3.00 & 2.61 & 3.57 & $.39(-.27,1.06)$ & $-.57(-1.63, .49)$ & $-.96(-1.89,-.04)$ & Not Clear \\
\hline LMX7 & 4.29 & 2.39 & 2.14 & $1.89(1.16,2.63)$ & $2.14(1.39,2.89)$ & $.25(-.32, .82)$ & Cognitive \\
\hline MDM-AFF1** & 2.14 & 4.75 & 1.57 & $-2.61(-3.33,-1.89)$ & $.57(.02,1.12)$ & $3.18(2.63,3.73)$ & Affect \\
\hline MDM-AFF2 & 3.07 & 4.11 & 1.71 & $-1.04(-2.02,-.05)$ & $1.36(.58,2.13)$ & $2.39(1.75,3.04)$ & Affect \\
\hline MDM-AFF3 & 2.82 & 4.39 & 2.07 & $-1.57(-2.41,-.73)$ & $.75(-.03,1.53)$ & $2.32(1.59,3.05)$ & Affect \\
\hline MDM-LOY1 & 3.71 & 2.07 & 2.46 & $1.64(.78,2.50)$ & $1.25(.10,2.39)$ & $-0.39(-1.01, .23)$ & Cognitive \\
\hline MDM-LOY2 & 3.36 & 2.39 & 2.86 & $.96(.08,1.85)$ & $.50(-.73,1.73)$ & $-.46(-1.29, .36)$ & Not Clear \\
\hline MDM-LOY3 & 3.61 & 2.36 & 2.82 & $1.25(.39,2.11)$ & $.79(-.36,1.93)$ & $-.46(-1.28, .35)$ & Not Clear \\
\hline MDM-CON1 & 2.25 & 1.93 & 4.64 & $.32(-.28, .92)$ & $-2.34(-3.14,-1.64)$ & $-2.71(-3.42,-2.01)$ & Behavior \\
\hline
\end{tabular}




\begin{tabular}{|c|c|c|c|c|c|c|c|}
\hline MDM-CON2 & 1.96 & 2.00 & 4.71 & $-.04(-.61, .54)$ & $-2.75(-3.42,-2.08)$ & $-2.71(-3.35,-2.08)$ & Behavior \\
\hline MDM-CON3 & 2.25 & 1.86 & 4.61 & $.39(-.16, .95)$ & $-2.36(-3.03,-1.69)$ & $-2.75(-3.31,-2.19)$ & Behavior \\
\hline MDM-RES1 & 4.21 & 2.82 & 1.82 & $1.39(.54,2.25)$ & $2.39(1.63,3.16)$ & $1.00(.28,1.72)$ & Cognitive \\
\hline MDM-RES2 & 3.86 & 3.36 & 1.71 & $.50(-.49,1.49)$ & $2.14(1.50,2.78)$ & $1.64(1.05,2.23)$ & Not Clear \\
\hline MDM-RES3 & 3.46 & 3.86 & 1.54 & $-.39(-1.35, .57)$ & $1.93(1.31,2.54)$ & $2.32(1.78,2.86)$ & Not Clear \\
\hline TL1*** & 3.96 & 1.61 & 2.32 & $2.36(1.71,3.01)$ & $1.64(.59,2.69)$ & $-.71(-1.22,-.21)$ & Cognitive \\
\hline TL2 & 4.00 & 2.21 & 1.93 & $1.79(1.01,2.56)$ & $2.07(1.18,2.97)$ & $.29(-.44,1.01)$ & Cognitive \\
\hline TL3 & 4.61 & 1.79 & 1.57 & $2.82(2.34,3.31)$ & $3.04(2.57,3.50)$ & $.21(-.19, .61)$ & Cognitive \\
\hline TL4 & 4.21 & 2.25 & 1.86 & $1.96(1.25,2.68)$ & $2.36(1.59,3.13)$ & $.39(-.23,1.01)$ & Cognitive \\
\hline TL5 & 4.00 & 1.82 & 2.36 & $2.18(1.53,2.83)$ & $1.64(.65,2.63)$ & $-.54(-1.19, .12)$ & Cognitive \\
\hline TL6 & 4.25 & 2.25 & 2.21 & $2.00(1.35,2.65)$ & $2.04(1.19,2.89)$ & $.04(-.53, .59)$ & Cognitive \\
\hline TL7 & 3.96 & 2.00 & 2.61 & $1.96(1.35,2.58)$ & $1.36(.29,2.42)$ & $-.61(-1.33, .11)$ & Cognitive \\
\hline TL8 & 3.96 & 1.82 & 2.71 & $2.14(1.56,2.73)$ & $1.25(.15,2.34)$ & $-.89(-1.54,-.25)$ & Cognitive \\
\hline TL9 & 3.86 & 2.39 & 2.54 & $1.46(.63,2.30)$ & $1.32(.34,2.30)$ & $-.14(-.90, .62)$ & Cognitive \\
\hline TL10 & 3.79 & 2.18 & 2.61 & $1.61(.84,2.38)$ & $1.18(.09,2.26)$ & $-.43(-1.19, .33)$ & Cognitive \\
\hline TL11 & 4.04 & 2.29 & 2.43 & $1.75(.98,2.52)$ & $1.61(.65,2.57)$ & $-.14(-.82, .54)$ & Cognitive \\
\hline
\end{tabular}




\begin{tabular}{|c|c|c|c|c|c|c|c|}
\hline TL12 & 4.32 & 2.07 & 2.07 & $2.25(1.56,2.94)$ & $2.25(1.49,3.00)$ & $.00(-.54, .54)$ & Cognitive \\
\hline TL13 & 4.21 & 2.07 & 2.25 & $2.14(1.44,2.85)$ & $1.96(1.20,2.73)$ & $-.18(-.81, .46)$ & Cognitive \\
\hline TL14 & 4.14 & 1.96 & 2.21 & $2.18(1.58,2.78)$ & $1.93(1.05,2.81)$ & $-.25(-.82, .32)$ & Cognitive \\
\hline TL15 & 3.29 & 3.21 & 2.36 & $.07(-.91,1.06)$ & $.93(.07,1.79)$ & $.86(.15,1.56)$ & Not Clear \\
\hline TL16 & 3.46 & 3.61 & 2.11 & $-.14(-1.15, .87)$ & $1.36(.65,2.07)$ & $1.50(.89,2.10)$ & Not Clear \\
\hline TL17 & 3.54 & 2.96 & 2.68 & $.57(-.21,1.36)$ & $.86(-.16,1.88)$ & $.29(-.56,1.13)$ & Not Clear \\
\hline TL18 & 3.46 & 3.21 & 2.18 & $.25(-.69,1.19)$ & $1.29(.42,2.15)$ & $1.04(.33,1.74)$ & Not Clear \\
\hline TL19 & 4.43 & 2.07 & 2.25 & $2.36(1.83,2.89)$ & $2.18(1.46,2.89)$ & $-.18(-.59, .23)$ & Cognitive \\
\hline TL20 & 4.57 & 1.86 & 2.36 & $2.71(2.24,3.19)$ & $2.21(1.57,2.86)$ & $-2.71(-3.19,-2.24)$ & Cognitive \\
\hline TL21 & 4.25 & 1.96 & 2.36 & $2.29(1.61,2.96)$ & $1.89(1.17,2.62)$ & $-.39(-1.02, .24)$ & Cognitive \\
\hline TL22 & 4.18 & 2.75 & 2.39 & $1.43(.63,2.23)$ & $1.79(1.08,2.49)$ & $.36(-.42,1.13)$ & Cognitive \\
\hline ALQ1**** & 4.11 & 2.04 & 2.54 & $2.07(1.42,2.72)$ & $1.57(.59,2.55)$ & $-.50(-.99,-.01$ & Cognitive \\
\hline ALQ2 & 4.11 & 1.89 & 2.43 & $2.21(1.61,2.82)$ & $1.68(.72,2.63)$ & $-.54(-1.14, .07)$ & Cognitive \\
\hline ALQ3 & 4.36 & 1.93 & 2.57 & $2.43(1.81,3.05)$ & $1.79(.91,2.67)$ & $-.64(-1.28,-.01)$ & Cognitive \\
\hline ALQ4 & 4.18 & 1.96 & 2.54 & $2.21(1.55,2.88)$ & $1.64(.66,2.63)$ & $-.57(-1.27, .12)$ & Cognitive \\
\hline ALQ5 & 4.29 & 1.89 & 2.54 & $2.39(1.87,2.91)$ & $1.75(.86,2.64)$ & $-.64(-1.29, .01)$ & Cognitive \\
\hline
\end{tabular}




\begin{tabular}{|llllllll} 
ALQ6 & 4.07 & 2.11 & 2.54 & $1.96(1.36,2.57)$ & $1.54(.58,2.49)$ & $-.43(-1.07, .21)$ & Cognitive \\
ALQ7 & 4.36 & 1.96 & 2.25 & $2.39(1.75,3.04)$ & $2.11(1.40,2.81)$ & $-.29(-.82, .25)$ & Cognitive \\
ALQ8 & 4.07 & 2.00 & 2.54 & $2.07(1.41,2.73)$ & $1.54(.58,2.49)$ & $-.54(-1.15, .08)$ & Cognitive \\
ALQ9 & 4.32 & 2.00 & 2.25 & $2.32(1.75,2.89)$ & $2.07(1.36,2.79)$ & $-.25(-.78, .28)$ & Cognitive \\
ALQ10 & 3.96 & 2.07 & 2.82 & $1.89(1.26,2.53)$ & $1.14(.17,2.11)$ & $-.75(-1.39,-.10)$ & Cognitive \\
ALQ11 & 4.11 & 2.21 & 2.29 & $1.89(1.09,2.69)$ & $1.82(.99,2.65)$ & $-.07(-.62, .48)$ & Cognitive \\
ALQ12 & 4.43 & 1.61 & 2.18 & $2.82(2.27,3.37)$ & $2.25(1.42,3.09)$ & $-.57(-1.07,-.07)$ & Cognitive \\
ALQ13 & 4.43 & 2.14 & 1.93 & $2.29(1.71,2.86)$ & $2.50(1.83,3.17)$ & $.21(-.34, .77)$ & Cognitive \\
ALQ14 & 4.29 & 2.04 & 2.54 & $2.25(1.60,2.89)$ & $1.75(.86,2.64)$ & $-.50(-1.15, .15)$ & Cognitive \\
ALQ15 & 4.21 & 2.29 & 2.07 & $1.93(1.09,2.76)$ & $2.14(1.45,2.84)$ & $.21(-.29, .72)$ & Cognitive \\
ALQ16 & 4.00 & 2.18 & 2.71 & $1.82(1.19,2.45)$ & $1.29(.30,2.27)$ & $-.54(-1.21, .14)$ & Cognitive \\
\hline
\end{tabular}

$\mathrm{N}=28$ Raters. All Scale items can be found in appendix 1

*LMX $=$ LMX-7 (Graen \& Uhl-Bien, 1995)

** LMX-MDM $(\mathrm{AFF}=$ Affect, $\mathrm{LOY}=$ Loyalty, CON = Contribution, RES = Professional Respect; Liden \& Maslyn, 1998)

***Transformational Leadership Inventory (Podsakoff et al. 1990)

****Authentic Leadership Questionnaire (Neider, \& Schriesheim, 2011).

Note. Mean difference is significant if the $95 \%$ confidence interval does not include zero. 
Table 3: Definitions and Measurement of the Different Facets of Attitude Strength

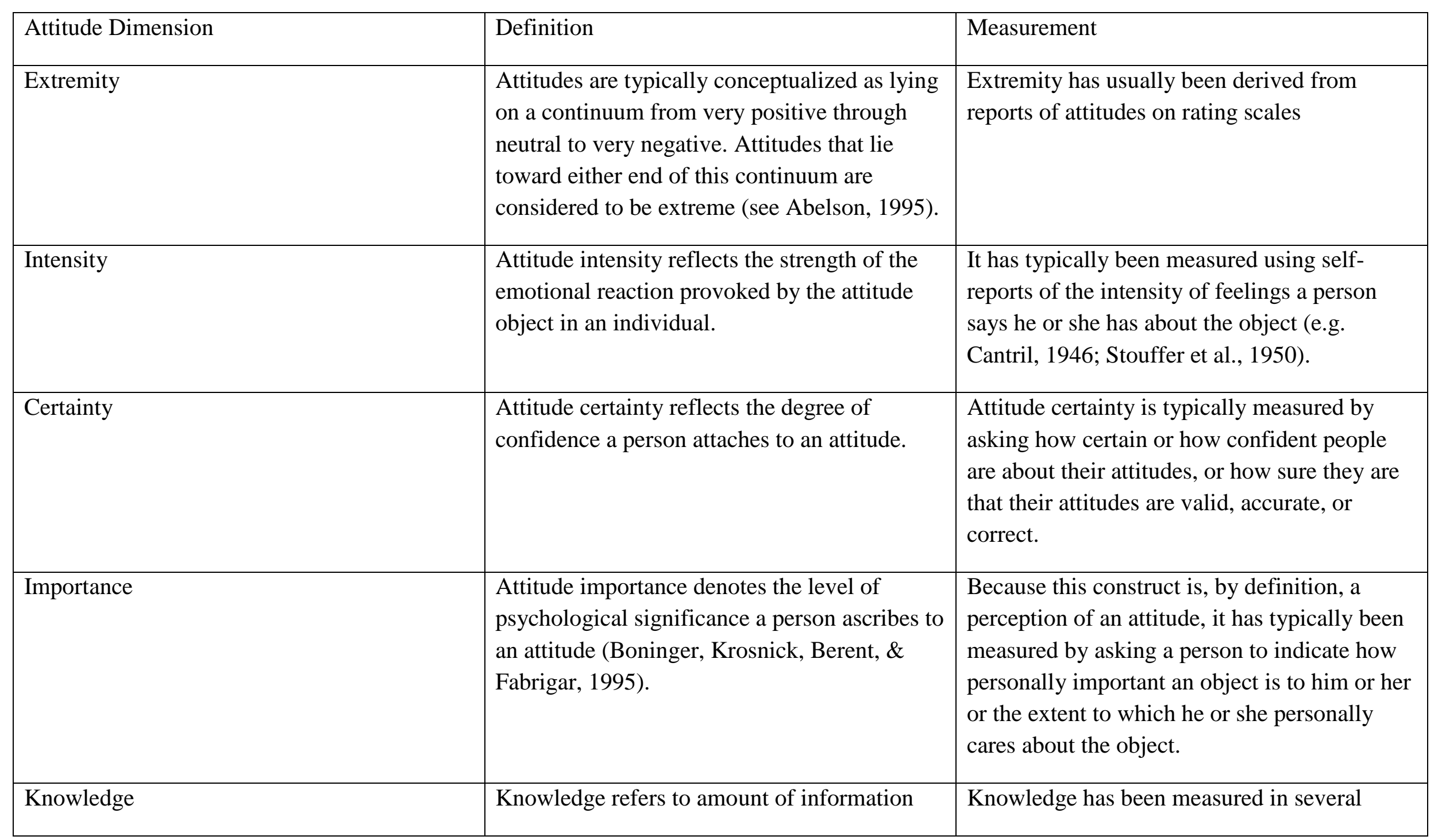




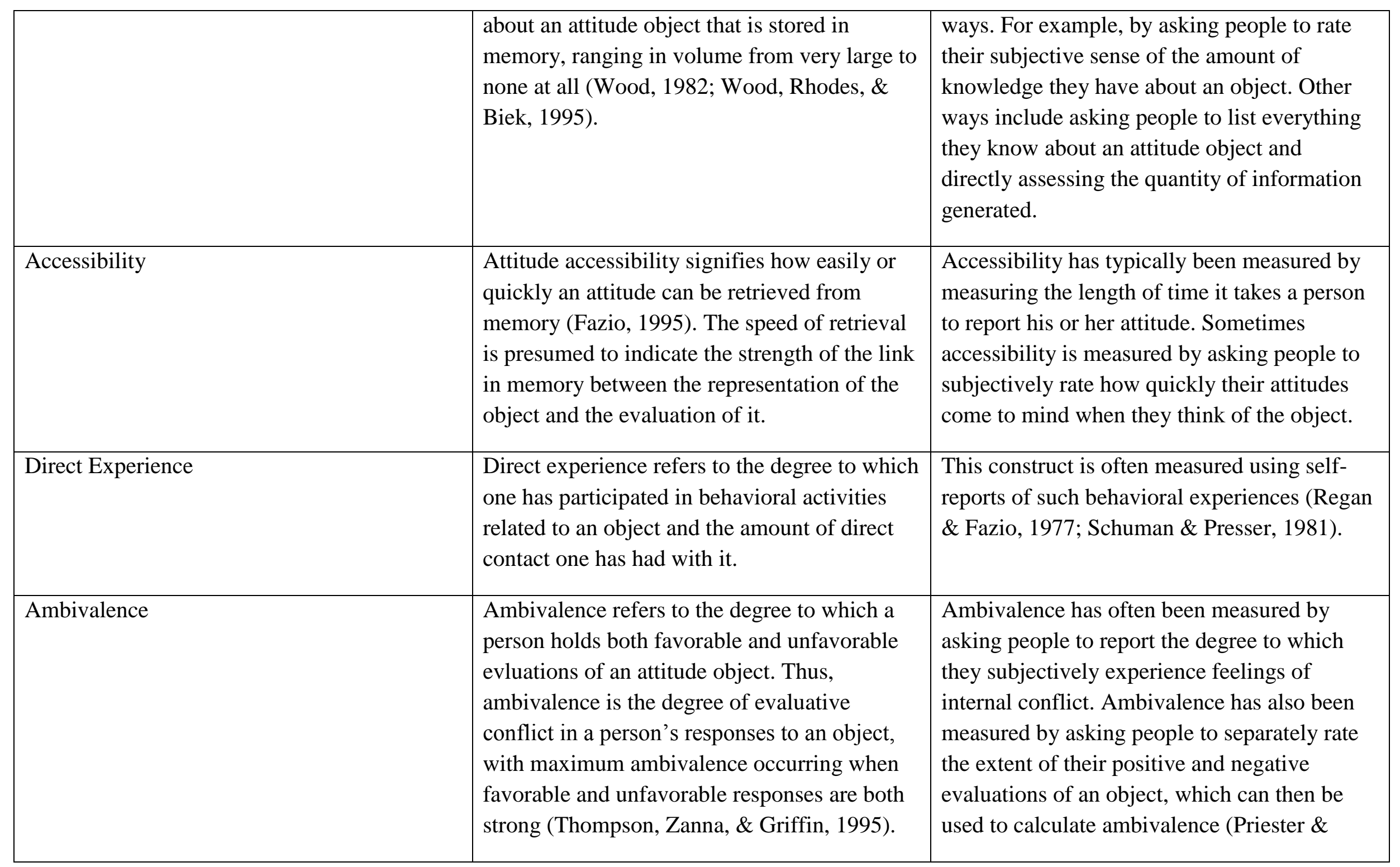




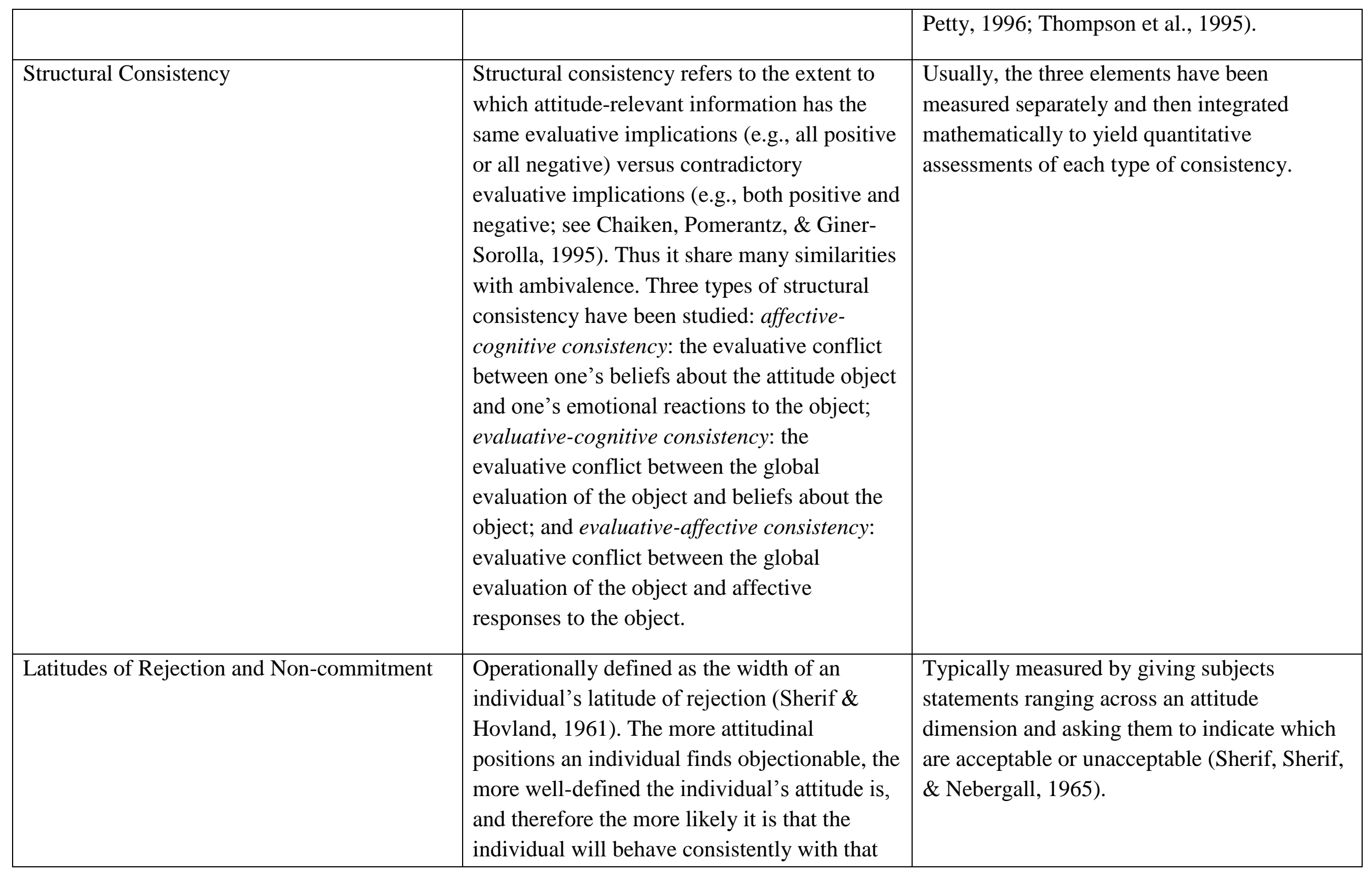




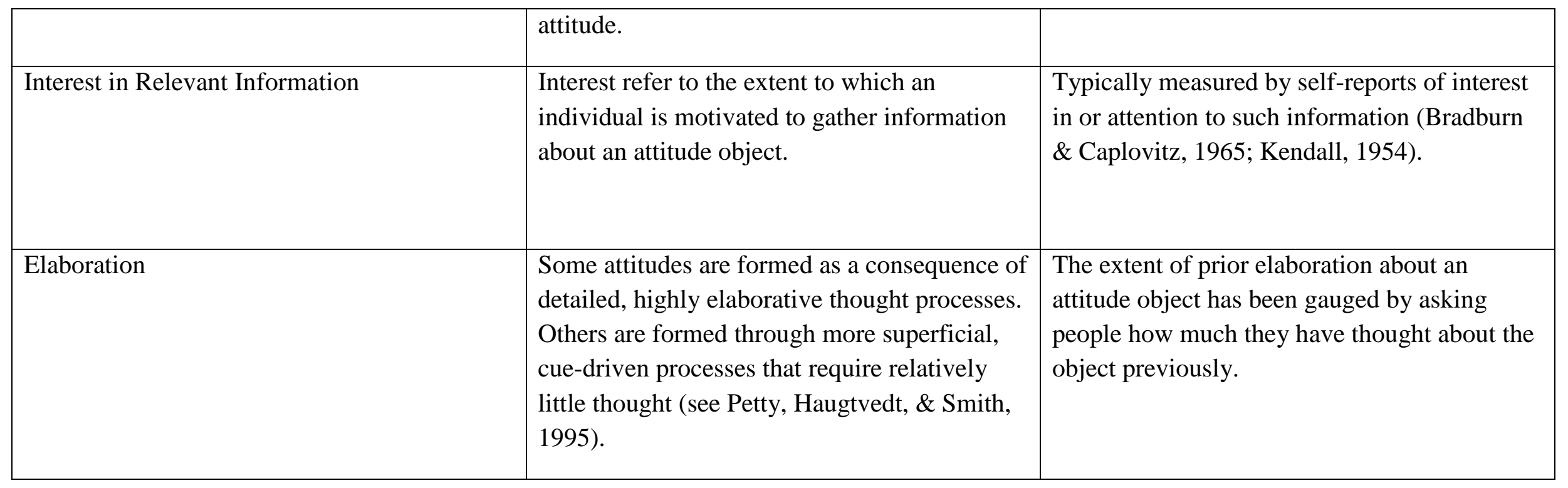


Appendix 1 - Items from leadership scales included in table 2

\section{LMX-7 (Graen \& Uhl-Bien, 1995)}

LMX1: Do you know where you stand with your leader .. do you usually know how satisfied your leader is with what you do? (rated: Rarely to Very Often)

LMX2: How well does your leader understand your job problems and needs? (rated: Not a Bit to A Great Deal)

LMX3: How well does your leader recognize your potential? (rated: Not at All to Fully)

LMX4: Regardless of how much formal authority he/she has built into his/her position, what are the chances that your leader would use his/her power to help you solve problems in your work? (rated: None to Very High)

LMX5: Again, regardless of the amount of formal authority your leader has, what are the chances that he/she would "bail you out," at his/her expense? (rated: None to Very High)

LMX6: I have enough confidence in my leader that I would defend and justify his/her decision if he/she were not present to do so? (rated: Strongly Disagree to Strongly Agree)

LMX7: How would you characterize your working relationship with your leader? (rated: extremely ineffective to extremely effective)

\section{LMX-MDM (Liden \& Maslyn, 1998)}

\section{Affect Dimension}

MDM-AFF1: I like my supervisor very much as a person

MDM-AFF2: My supervisor is the kind of person one would like to have as a friend MDM-AFF3: My supervisor is a lot of fun to work with

\section{Loyalty Dimension}

MDM-LOY1: My supervisor defends my work actions to a superior, even without complete knowledge of the issue in question

MDM-LOY2: My supervisor would come to my defense if I were 'attacked' by others

MDM-LOY3: My supervisor would defend me to others in the organization if I made an honest mistake

\section{Contribution Dimension}

MDM-CON1: I am willing to apply extra efforts, beyond those normally required, to further the interests of my work group

MDM-CON2: I do work for my supervisor that goes beyond what is specified in my job description 
MDM-CON3: I do not mind working my hardest for my supervisor

\section{Professional Respect Dimension}

MDM-RES1: I respect my supervisor's knowledge of and competence on the job

MDM-RES2: I am impressed with my supervisor's knowledge of his/her job

MDM-RES3: I admire my supervisor's professional skills

\section{Transformational Leadership Inventory (Podsakoff et al. 1990)}

TL1: My supervisor is always seeking new opportunities for the unit/department/organization

TL2: My supervisor paints an interesting picture of the future for our group

TL3: My supervisor has a clear understanding of where we are going

TL4: My supervisor is able to get others committed to his/her dream of the future

TL5: My supervisor leads by "doing" rather than simply "telling"

TL6: My supervisor provides a good model to follow

TL7: My supervisor leads by example

TL8: My supervisor fosters collaboration among work groups

TL9: My supervisor encourages employees to be "team players"

TL10: My supervisor gets the group to work together for the same goal

TL11: My supervisor develops a team attitude and spirit among his/her employees

TL12: My supervisor shows that he/she expects a lot from us

TL13: My supervisor insists on only the best performance

TL14: My supervisor will not settle for second best

TL15: My supervisor acts without considering my feelings

TL16: My supervisor shows respect for my personal feelings

TL17: My supervisor behaves in a manner that is thoughtful of my personal needs

TL18: My supervisor treats me without considering my personal feelings

TL19: My supervisor has provided me with new ways of looking at things which used to puzzle me

TL20: My supervisor has ideas that have forced me to rethink some of my own ideas that I have never questioned before.

TL21: My supervisor has stimulated me to think about old problems in new ways 
TL22: My supervisor inspires others with his/her plans for the future

\section{Authentic Leadership Questionnaire (Neider, \& Schriesheim, 2011).}

ALQ1: My leader solicits feedback for improving his/her dealings with others ALQ2: My leader clearly states what he/she means

ALQ3: My leader shows consistency between his/her beliefs and actions

ALQ4: My leader asks for ideas that challenge his/her core beliefs

ALQ5: My leader describes accurately the way that others view his/her abilities

ALQ6: My leader admits mistakes when they occur

ALQ7: My leader uses his/her core beliefs to make decisions

ALQ8: My leader carefully listens to alternative perspectives before reaching a conclusion ALQ9: My leader shows that he/she understands his/her strengths and weaknesses ALQ10: My leader openly shares information with others

ALQ11: My leader resists pressures on him/her to do things contrary to his/her beliefs ALQ12: My leader objectively analyzes relevant data before making a decision ALQ13: My leader is clearly aware of the impact he/she has on others ALQ14: My leader expresses his/her ideas and thoughts clearly to others ALQ15: My leader is guided in his/her actions by internal moral standards ALQ16: My leader encourages others to voice opposing points of view. 
